\title{
DEVELOPMENT OF A CONTINUOUS DUTY CRYOPUMP
}

\author{
prepared for \\ Lawrence Livermore National Laboratory \\ in response $t$ \\ PO 2024005 of Contract W-7405-ENG-4L \\ by Douglas W. Sedgley \\ Grumman Space Division \\ an operating division of Grumman Corporation \\ Bethpage, NY 11714
}

and

Thomas H. Batger

Wayne R. Call

Lawrence Livermore National Laboratory

Livermore, CA 94550

DISCLAIMER

This report was prepared as an 2ccount of work sponsored by an agency of the United Slates Governmenl. Neither the United States Government nor any agency thereof, nor any of their employeses, makes any warranty, express or implied, or assumes any legal liability or ronsibility for the accuracy, completeness, of usefulness of any information, apparatus, product, or process disclosed, or represents that its use would not infringe privately owned rights. Reference berein to any specific commercial product, process, ur service by trade name, trademart, manufacturer, or otherwise does not recessatily constitule of imply its endorsement, recommendation, or favoring by the Uniled States Government or any agency thereof. The viem and opinions of authors expresserl herein do not necessarily state or reflect those of the Uaited St ates crovernment or any agency theroof. 
CONTENTS

Section $\quad \underline{\text { Page }}$

1 abSTRACT. ..................... 1. . . .

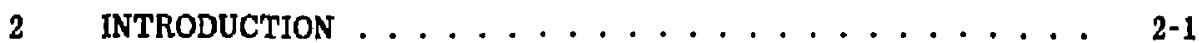

3 PROGRAM OBJECTIVE ................... 3-1

4 CRYOPUMP SYSTEM DESCRIPTION . . . . . . . . . . 4-1

4.1 Cryopump ...................... 4-1

4.2 Controller...................... $4-2$

5 TEST PROGRAM ................... 5-1

5.1 Test Apparatus ................ 5-1

5.2 Test Pump .................... 5-2

5.3 Instrumentation \& Control ................ 5-3

6 TEST PROCEDURE . . . . . . . . . . . . . . . 6-1

6.1 Preparation for Test. ................ 6-1

6.2 Direct Mode Test . . . . . . . . . . . . . . 6-1

6.3 Back Leakage Test ............. . . . . . 6-2

6.4 Automatic Mode Test. . . . . . . . . . . . . . . . 6-2

7 TEST RESULTS ....................... $7-1$

7.1 Pretest Conditioning. ................ 7-1

7.2 Pump Performance. . . . . . . . . . . . . . 7-2

7.3 Back Leakage During Regeneration ............. 7-4

7.4 Cryopump System Continuous Operation . . . . . . . . . 7-6

$8 \quad$ DISCUSSION . . . . . . . . . . . . . . . . 8-1

8.1 Pretest Evaluation.................. 8-1

8.2 Pump Performance. . . . . . . . . . . . . 8-1 


\section{CONTENTS (contd)}

Section

Page

8.3 Back Leakage During Regeneration . . . . . . . . 8-2

8.4 Cryopump System Continuous Operation .......... 8-3

g CONCLUSIONS ..................... ... $9-1$

10 REFERENCES ....................... 10 . . . 1 


\section{ILLUSTRATIONS}

Fig. Page

Continuous Duty Cryopump Installation . . . . . . . . . 4-2

2 Cryopump Controller ..................... . 4-3

3 Liquid Helium-Cooled Deuterium Pumping Panels. . . . . . . . . . 4-4

4 Z-Shaped Louver Shields . ............... 4-5

5 Actuator Assembly for Louver Doors . . . . . . . . . . . . 4-6

6 Collector Pump Shown in the Cryopump. . . . . . . . . . 4-6

7 Cryogenic Distribution System ............... 4-7

8 Control Console ... . . . . . . . . . . . . . . . 4-8

9 Test Facility Overview . . . . . . . . . . . . . . 5-2

10 Plan View of Test Setup ................... . . 5-3

11 Automatic Valve in Helium Transfer Line .............. 5-4

12 Schematic of Helium Control Valves .............. 5-5

13 Location of Temperature Sensors on Cryopump . . . . . . . . 5-6

14 Valve/Actuator Positions .................. 6-3

15 Survey of Cryopump Temperatures . . . . . . . . . . . 7-1

16 Deuterium Pumping Performance of the Continuous Duty Cryopump ........................ 7-3

17A Vacuum Chamber Pressure History During Regeneration, . . . . . 7-5

17 Vacuum Chamber Pressure History During Regeneration. . . . . . . 7-6

18 Vacuum Chamber History During Regeneration .......... 7-7

19 Vacuum Chamber Pressure History During Regeneration. . . . . . 7-8

20 Vacuum Chamber Pressure History During Regeneration. . . . . . . 7-9

21 Vacuum Chamber Pressure History During Panel Regeneration .................... 7-10

22 Vacuum Chamber Pressure History During Collector Pump Regeneration . . . . . . . . . . . . . . . . . . . 7-11

23 Typical Regeneration Teniperature Profile (Panel 1) . . . . . . . . 7-12

24 Peak Chamber Pressure Irom Backleakage During Regeneration of Test Cryopump . . . . . . . . . . . . . . . . 8-2 


\section{1 - ABSTRACT}

The continuous output of large quantities of gases at low pressure from fusion reactors, principally helium and hydrogen isotopes, dictates the need for a high speed pumping system that operates continuously, efficiently, and automatically. A liquid helium-cooled cryopump operated by a microprocessor controller can meet these requirements. The prototype system described herein features a single cryopump with three distinct pumping units: two units for pumping the vacuum chamber arranged so that one unit is closed for regenerating while the other is pumping the chamber ( 100 s redundancy); and a collector pump, which is a high speed aryopump for receiving the regenerated gas. The unit pumps deuterium but can be changed readily to a sorption pump for helium service.

The eryopump system is operated continuously with commands issued by the contrcller software. Deuterium pumping speed referenced to the pump's inlet area was over 11 liter sec ${ }^{-1} \mathrm{~cm}^{-2}(17,400 \mathrm{liter} / \mathrm{s})$ at $10^{-5}$ Torr chamber pressure. Regeneration time was under six minutes. Gas leakage back to the vacuum chamber during degassing was 7.58 and the pressure rose to $3.3 \times 10^{-4}$ Torr.

A typical cryopump system for reactor applicaticn will have 208 redundancy (i.e., five units pumping with one unit regenerating). For this installation, pressure rise during regeneration from an operating base of $10^{-5}$ Torr would be to $5 x$ $10^{-5}$ Torr. Tritium holdup in the cryopump system of a typical $1500 \mathrm{MW}$ reactor would be under $30 \mathrm{~g}$. 


\section{2 - INTRODUCTION}

Commercial fusion reactors will exhaust contimuously large volumes of gas, principally helium, deuterium, and tritium. Cryopumps can provide the high punping speed dictated by these devices, and the work undertnken in the progran described here, and in Ref. 1 and 2 shows the capability to plame all effuents continuously. Batzer and Call (Ref, 2) developed a unit for pumping devterium that can be installed directly into a vacuum chamber for efficient pumping and that con be regenernted without discharging the previously pumped gas back to the vacuum chamber. The unit demonstrated the fensibility of the regenerntion concept; testing of the unlt showed where design changes would improve regeneration elficiency. The unit was the prototype of the punp system whose testing is described in this report.

This pump system adds the capability of continuous operation. If features two pumping units, arranged so that one unit can be regenerated while the other unit is pumping. Although this arrangement is represcntative of a type that can provide the continuous operation required by fusion reactors, it is not an optimum arrangement because it represents 1008 redunduncy of pumping capacity. Batzer (Ref. 2) showed that this redundancy could be reduced to 20 s (i.e., five units pumping while one unit is being regenerate(l), while maintaining at $n$ low level the amount of gas (most importantly tritium) held in the cryopump. The arrangement with 203 redundancy would result, for example, in $\mathrm{n}$ tritium holdup of under $30 \mathrm{~g}$ in the cryopumps of a 1500 MIV fusion device (Ref. 3).

The continuous duty cryopunp is a vinble choice for reactor applicntion because of its ligh pumping speed and low gas inventory, coupled with ense of continuous operation as demonstrated by this progrum. 


\section{3 - PROGRAM OBJECTIVE}

The objective of this program was to test a deuterium cryopump system that was designed to operate continuously and be mounted within the vacuum chamber to be pumped. The design and fabrication phase was reported fully in Ref, 4 and 5 . The unique feature of this system was that, unlike typical in-vessel cryopumps, it did not release previously pumped gases back into the vacuum chamber during the pump's regeneration, and it operated continuously.

The precursor for the pumping eystem described in this report is a pump cepable of regeneration without significant back flow to the vacuum chamber (Ref 2). The objective of this referenced program was to show reliability, repeatibility, operational characteristics, and feasibility of the regeneration feature. That objective was met, and the program indicated the design features that could be modified to improve performance. The modifications were related principally to reducing back-leakage from the pump to the vacuum chamber during regeneration.

The information derived from testing of the continuous duty cryopump system includes:

- Deuterium pumping speed

- Effect of regeneration operation on vacuum chamber pressure

- Characteristics of automatic operation and time to regenerate. 


\section{4 - CRYOPUMP SYSTEM DESCRIPTION}

The continuous duty eryopump system consists of a cryopump (Fig. 1) that is self-contained for installation into a vacuum chamber and a microprocessor controller station (Fig. 2) for automatic operation. This section provides a summary description of the system, which is described fully in Ref, 4 and 5 .

\subsection{CRYOPUMP}

The pump consists of two pumping units in a single housing, arranged so that one is pumping while the other is regenerating.

Liquid helium-cooled, finned sections (Fig. 3) in each unit provide the surfaces for pumping of deuterium by condensation. Liquid nitrogen-cooled shields incorporating a 2-shaped double chevron configuration (Fig. 4) surround both units. The chevrons are equipped with hinged louvers at the apex of each chevron $V$, sn that the louvers can be closed for regeneration and open for pumping. A singlemechanism assembly (Fig. 5) using a driver and reversing link operates all louvers 80 that those of one pumping unit are driven closed while the other unit's louvers are opened simultaneously. A liquid helium-cooled collector pump (Fig. 6) integral within the shields, recondenses the pumped gas as it is evaporated from each pumping unit warmed up during regeneration. Doors, integral with the shield, separate each unit from the collector pump. Gas released from the collector pump during its regeneration is pumped by a mechanical roughing system.

The cryopump is fully maintainable. It is suspended through thermal isolators from a vacuum chamber cover, allowing the pump to be removed from the chamber by lifting the cover. The pump can be knocked down to its basic elements by undoing screws and mechanical fasteners. The entire shield, including pancls, bulkheads, door actuators, doors, thermal isolators, and structural supports, can be disassembled at the test site to allow removal of the helium-cooled pumping panels and the collector pump for examination and modification or repair as required. The valves, actuators, sensor feedthroughs, manifolds, and electrical connections on top of the chamber cover (Fig. 7) are similarly mounted for ready replacement. These units 


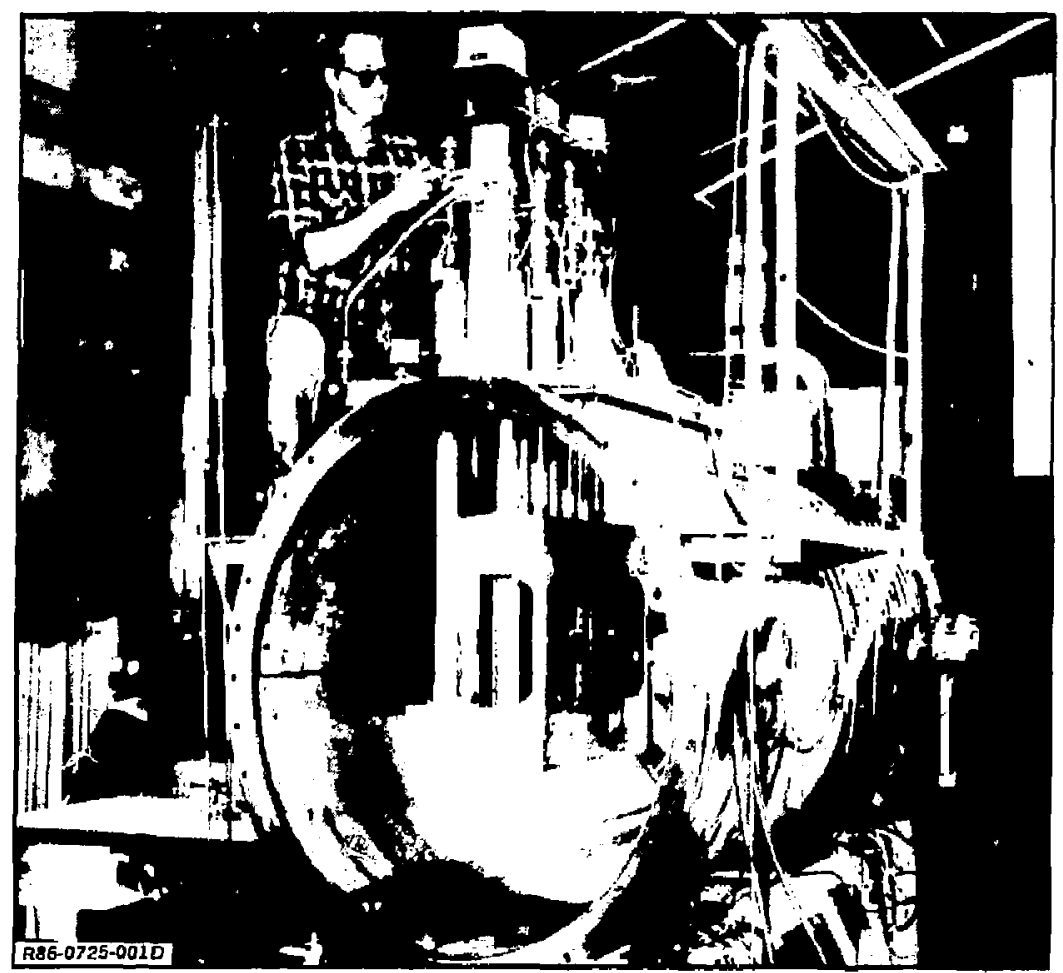

Fig. 1 Continuous Duty Cryopump Installation - The readily maintainable in - chamber pump is mounted on a cover for easy removal.

can be disassembled before pump removal from the chamber if hoisting, crane clearance is insufficient.

\subsection{CONTROLLER}

The control of cryogenic and ambient helium distribution for cooling and warming the pumping units, and operation of remote actuators, are performed by a programmable microprocessor unit (Fig. 8). Some valves on the collector pump are manually operated because their regeneration is done infrequently. Command software provides fully automatic, timed sequencing of the repetitive cryopump events. which are cooldown, operation, and regeneration. Automatic valve commands and event timing can be reprogrammed through a keybourd. An auto/direct override button allows the operator to interrupt automatic operation and control helium valves, louvers, nnd collector doors dirently through a switch panel. When the auto/direct button is engaged to the direct (manual) position, the operator can control the posi- 


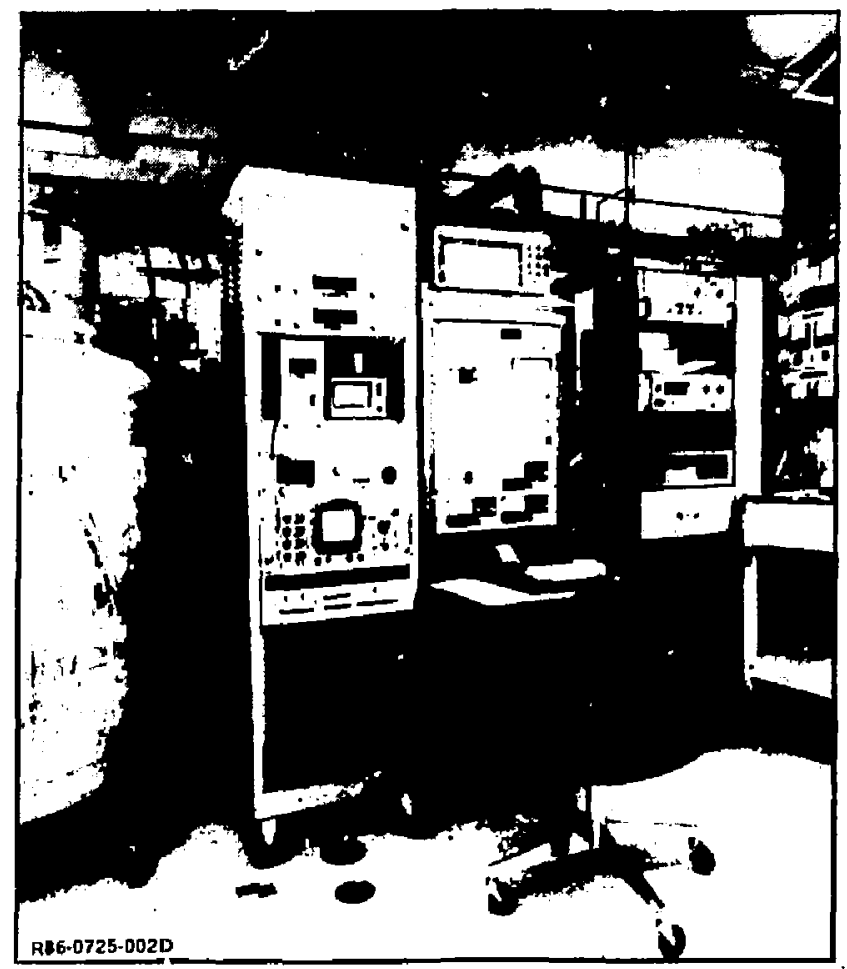

Fig. 2 Cryopump Controllur - Automatic or manual pump operation is implemented at the center console through the microprocessor or a switch panel. Pressures, temperatures, flow rates, and crogen levels are displayed.

tion of the valves, etc, regardless of whether the microprocessor is programmed or not. Temperatures and pressures are monitored and helium levels within the three pump reservoirs are held automatically. A voting subroutine compares helium fill commands from the command software and from liquid level controllers, and allows helium fill valves to open only when both commands are "fill." 


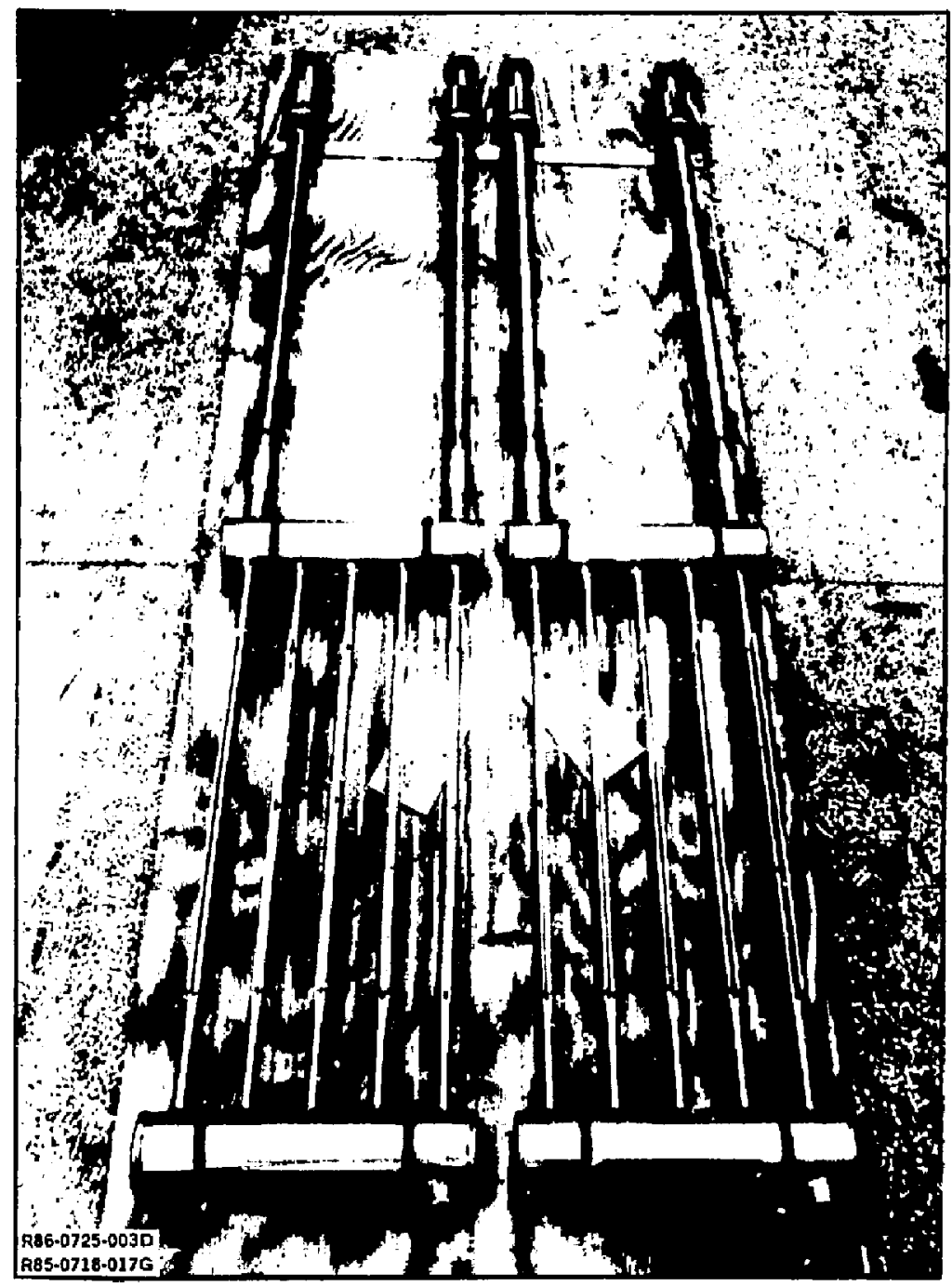

Fing. 3 Liquid Holium - Coolod Duturium Pumping Pands - Five fin-tube risers on each panef provice the pumping surface. 


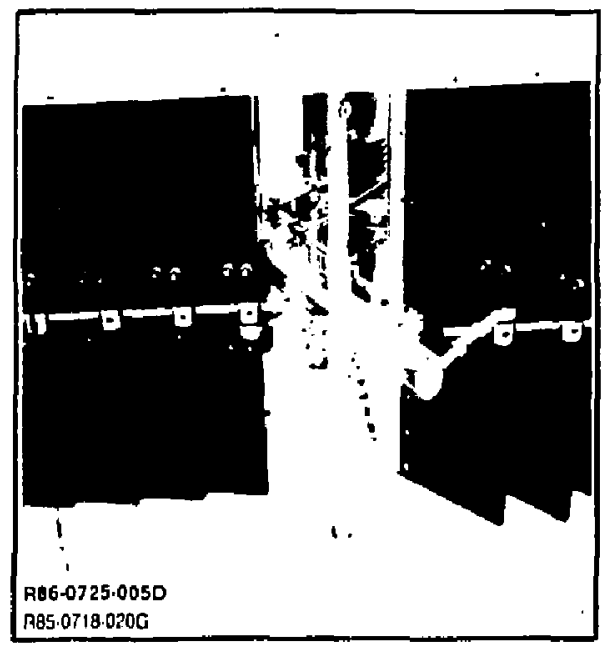

Fig. 5 Actustor Assembly for Louver Doors - A single reverser mechanism opens one unit and closes the other simultaneously.

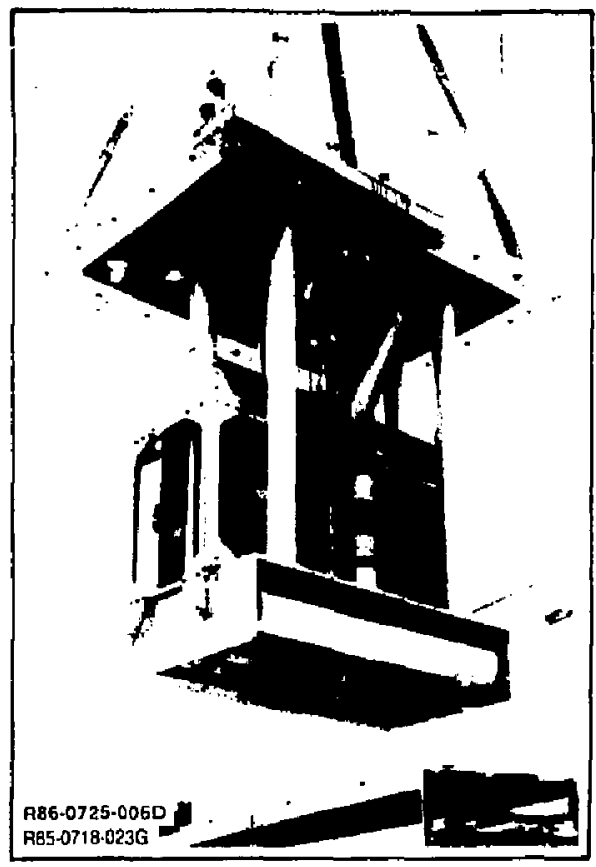

Fig. 6 Collector Pump Shown in the Cryopump - Tubular collector pump is separated from pumping unit by two doors shown in open pasition at bottarn with shield removed). 


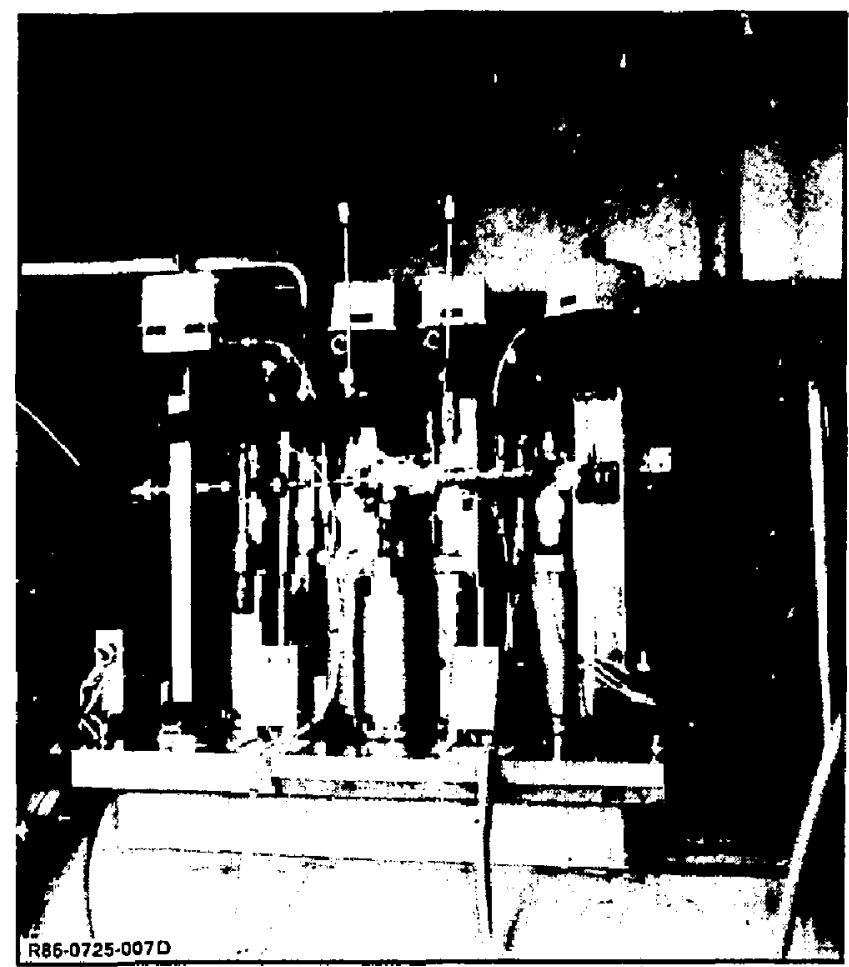

Fig. 7 Cyopenic Distribution System - Remote control valves control cnjogenic helium supply and return in a closed-loop system. Nitragen is vented. 


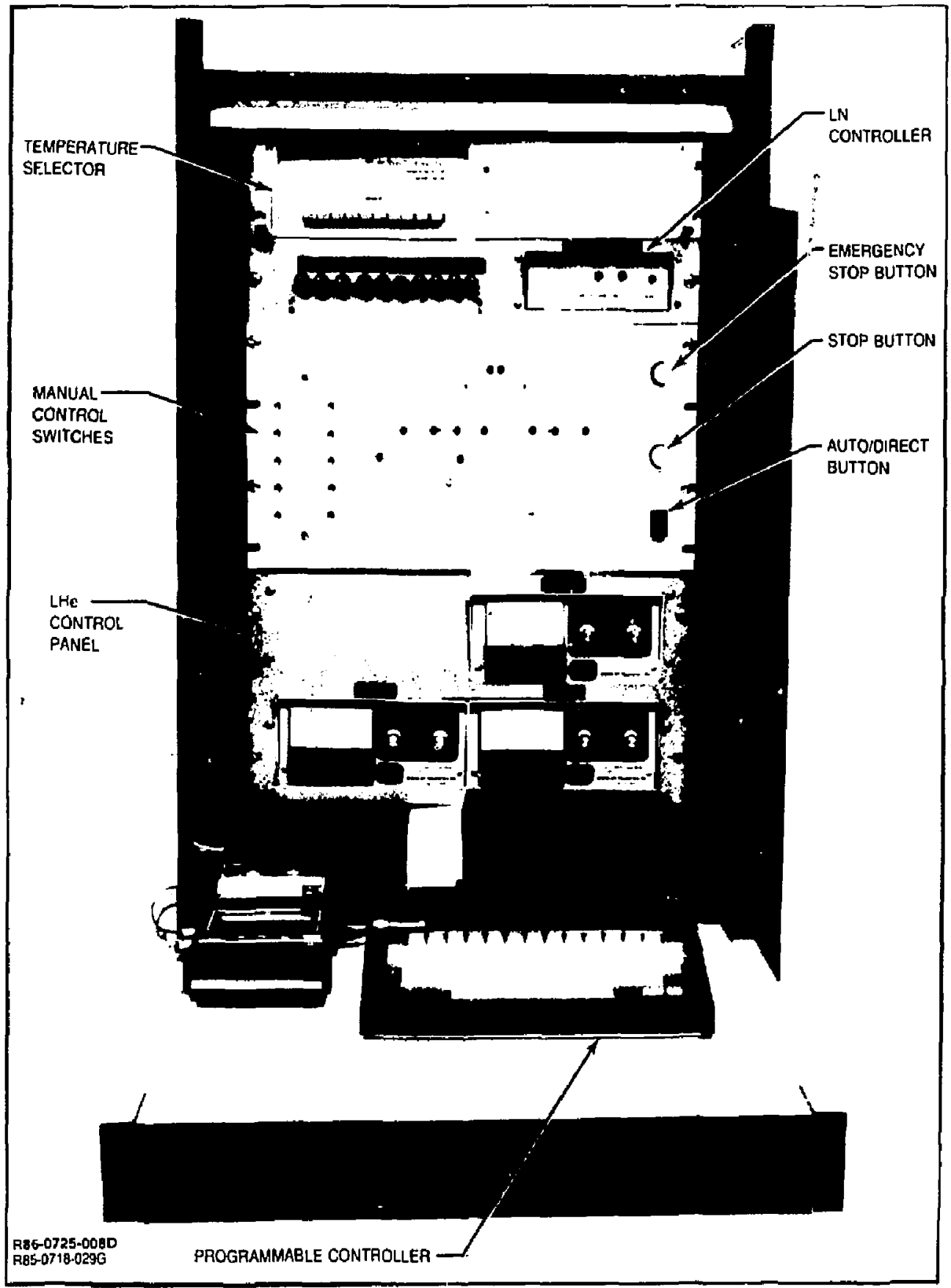

Fig. 8 Control Consol - Schematic panel provides status of control valves, collector doors, and louvers. Cassette stores the controller program. 


\section{5 - TEST PROGRAM!}

The test program was undertaken to determine experimentally the characteristics of the continuous duty cryopump system. The principal elements of the program were to establish the pump's cryogenic characteristics, operate the cryopump in manual mode, operate the cryopump system in automatic mode, evaluate back leakage, and determine deuterium pumping performance.

The vacuum test installation at the Lawrence Livermore National Laboratory (LLNL) Vacuum Technology Laboratory was used for the test program. The equipment and test procedures are described below.

\subsection{TEST APPARATUS}

The system used in the experimental study is shown pictorially in Fig. 9 and schematically in Fig. 10. The cryopump was installed in a vacuum chamber, which is a horizontal cylinder, approximately $1.2 \mathrm{~m}$ diameter by $3 \mathrm{~m}$ long, with appurtenances that yield a total estimated volume of $3.8 \mathrm{~m}^{3}$. Nomenclature describing the position of equipment refers to "east" or "west" because the cylinder's axes lay roughly on an east-west line. The cryopump hangs into the chamber from a cover installed atop the chamber's east end. Valves, manifolds, actuators, cryogen feedthroughs, and sensor feedthroughs are mounted on the cover (Fig. 7). Dewars supply liquid riitrogen and liquid helium through remote-controlled cryogenic volves (Fig. 11); expended helium from the pump is recovered and returned through a clnsed system to the collection system of a refrigerator/liquefier.

The west pumping station roughed the vacuum chamber and during test runs, the west end turbomolecular pump remained connected to the vacuum chamber to offset a small helium leak in one of the pump's LHe panels. The leak, estimated by test at $2.3 \times 10^{-5}$ Torr liter $\mathrm{s}^{-1}$, did not affect the deuterium pumping test results, for which the throughput, at a minimum, was three orders of magnitude higher. Knowing this leak inflow rate allowed calculation of the chamber volume by the pressure rise rate method with the pumping stations isolated, A recheck, 


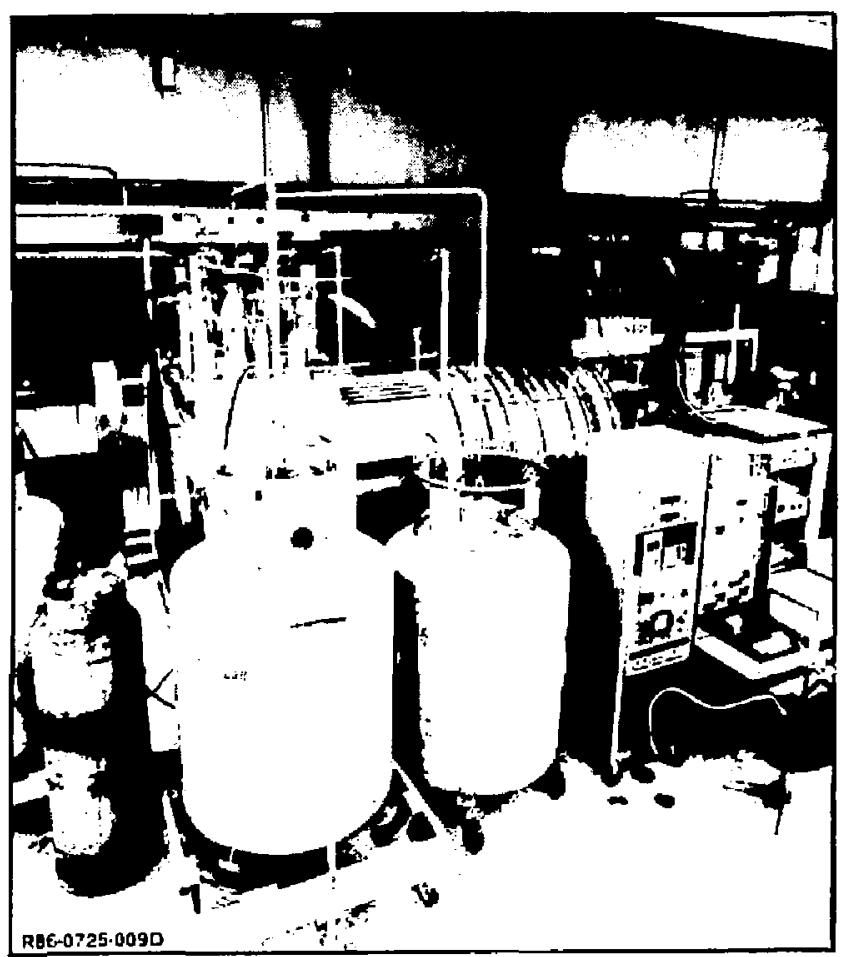

Fig. 9 Test Fucility Overvieiv - Helium is supplied in dewars from nearby liquefier to which vented helium is retumed directly.

determined by introducing a constant nitrogen flow and measuring pressure rise for one minute, resulted in a chamber volume final estimate of $3.8 \mathrm{~m}^{3}$ within \pm 28 .

Three flow meters cajubie of measuring the range of deuterium flows were placed in series with a servo-controlled valve. Deuterium flowrates, held constant during each performance run, ranged from 0.013 Torr liter $\mathrm{s}^{-1}$ to 13.6 Torr liter $\mathrm{s}^{-1}$. The pump design flow was 0.12 Torr liter $\mathrm{s}^{-1}$.

\subsection{TEST PUMP}

The continuous duty cryopump (described fully in Ref. 4 and briefly in Section 4) was mounted as shown in Fig. 1 with its louvers at the pump openings facing the chamber side walls. Deuterium entered the vacuum chamber at its side wall (Fig. 10) and was directed by a feed tube towards the west end. Each of the three pump elements within the cryopump, i.e., the two pumping units and the collector pump, 


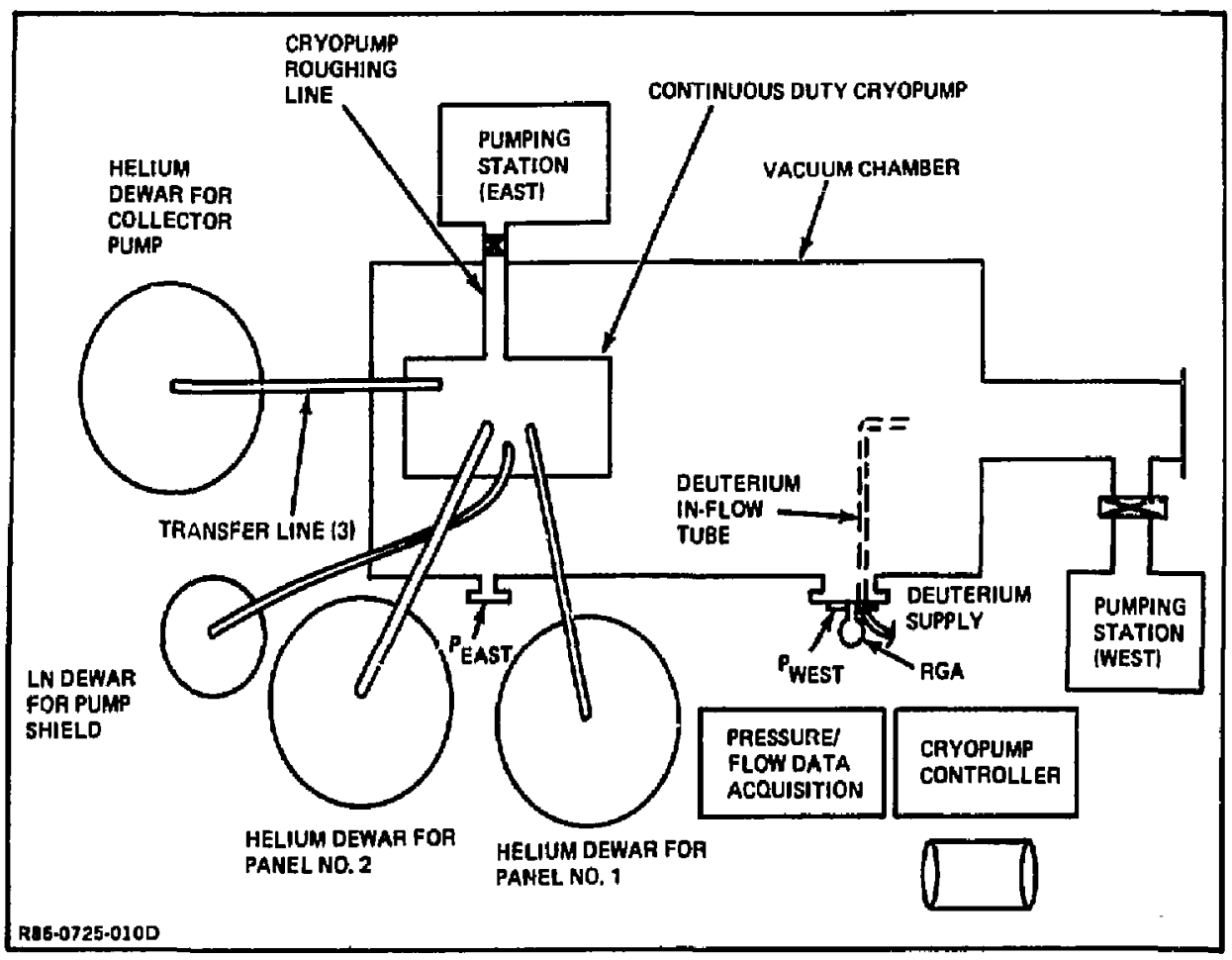

Fin. 10 Pian Viow of Tut Satup - The test cryopump removes deuterium from the chamber continuous/y. The west pumping station remuined connected to pump a small helium leak.

had the helium control manifold/valve arrangement shown in Fig. 12. This arrangement allowed helium filling/venting during cooldown and operating, and helium purging/dumping during regeneration. All helium was recovered for reliquefying.

Pumping unit valves, which operated for each operation/regeneration cycle, were operated remotely through the cryopump controller, whereas the collector pump valves, which were operated infrequently, were manual. A valve in the roughing line between the collector pump and the east pumping station was opened during collector pump regeneration.

\subsection{INSTRUMENTATION CONTROL}

Flow meters, temperature sensors, pressure gages, cryogenic level indicators, and a residual gas analyzer (RGA) monitored the condition of the tnst equipment and provided data. Flow meters indicated in terms of standard $\mathrm{cm}^{3}$ per minute (8ccm) of air. Flow meters with 0-5 and 0-50 scem (air) ranges were used for most test runs, 


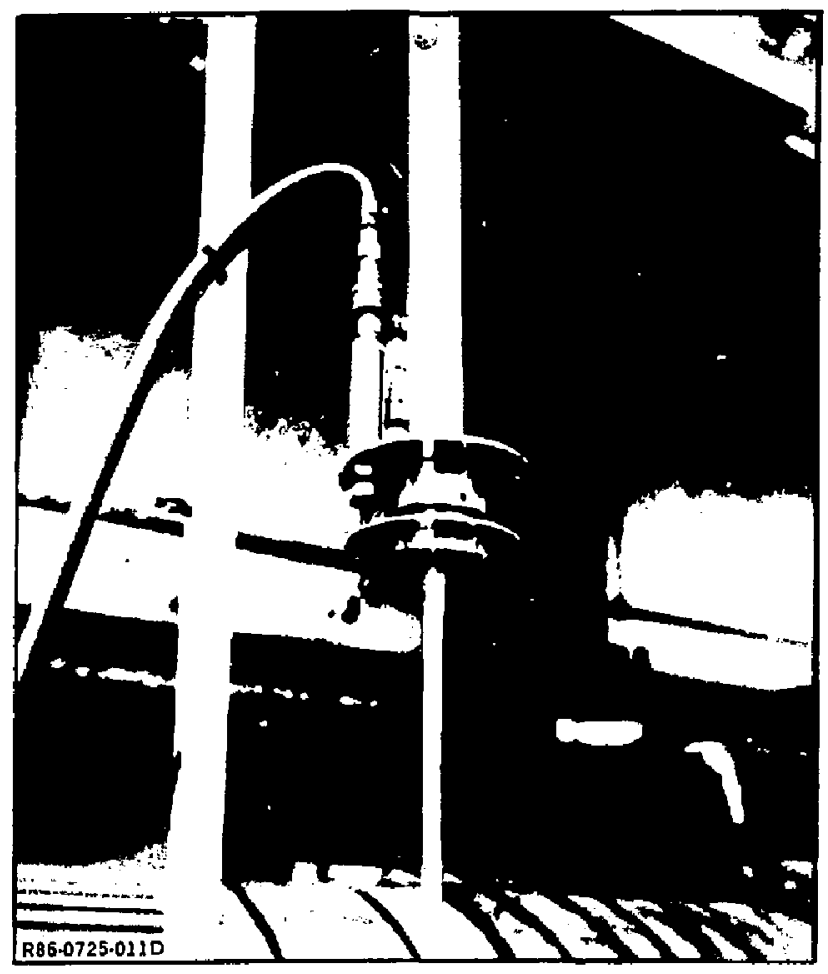

Fin, 11 Automatic Valve in Helium Transfer Lin - Air-operated cylinder controls the on off bayonet valive. Stroke of the valive is adjustable for control of flow rate.

and 8 0-1000 sccm (air) flow meter in series monitored flow for the high throughput run at 13.6 Torr liter $\mathrm{s}^{-1}$. The flow meter correction for deutcrium referenced to air is 1.07 .

Silicon diode sensors measured the temperatures on the cryopump louver, shield, pumping units, and collector door at the locations shown in Fig. 13. The sensors' celibrations provided by the manufacturer were verified in liquid helium in the laboratory. Bayard-Alpert-type nude ionization gages measured pressures in the vacuum chamber at the east and west locations shown in Fig. 10. The indicated pressure of these gages (calibrated for air) was multiplied by 2.5 for deuterium based on the manufacturer's data. A capacitance manometer gage monitored pressure within the pump's shield. 


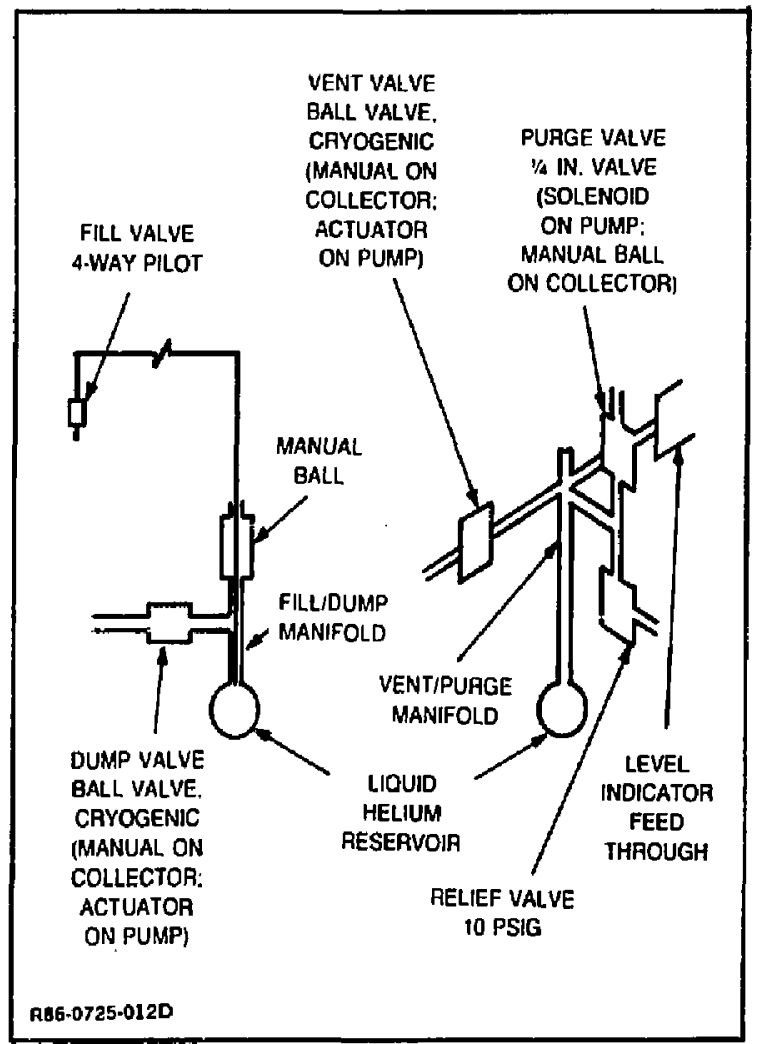

Fig. 12 Schematic of Helium Control Valven - Actuator vaives and solenoid valves are controlled remotely. Infrequently used colloctor values are manual.

Four cryogenic level probes and controllers maintained liquid content in the pump's dewars. Liquid nitrogen was supplied automatically by a controller responding to high and low level signals. The two pumping units and the collector pump had continuous reading superconducting probes that sent high/low signals to three level controllers. The corresponding helium fill valves responded to signals from the microprocessor (see Subsection 4.\%).

The RGA monitored the helium content in the vacuum chamber during leakchecking, after the pump was installed and cooled to operational condition before the test. 


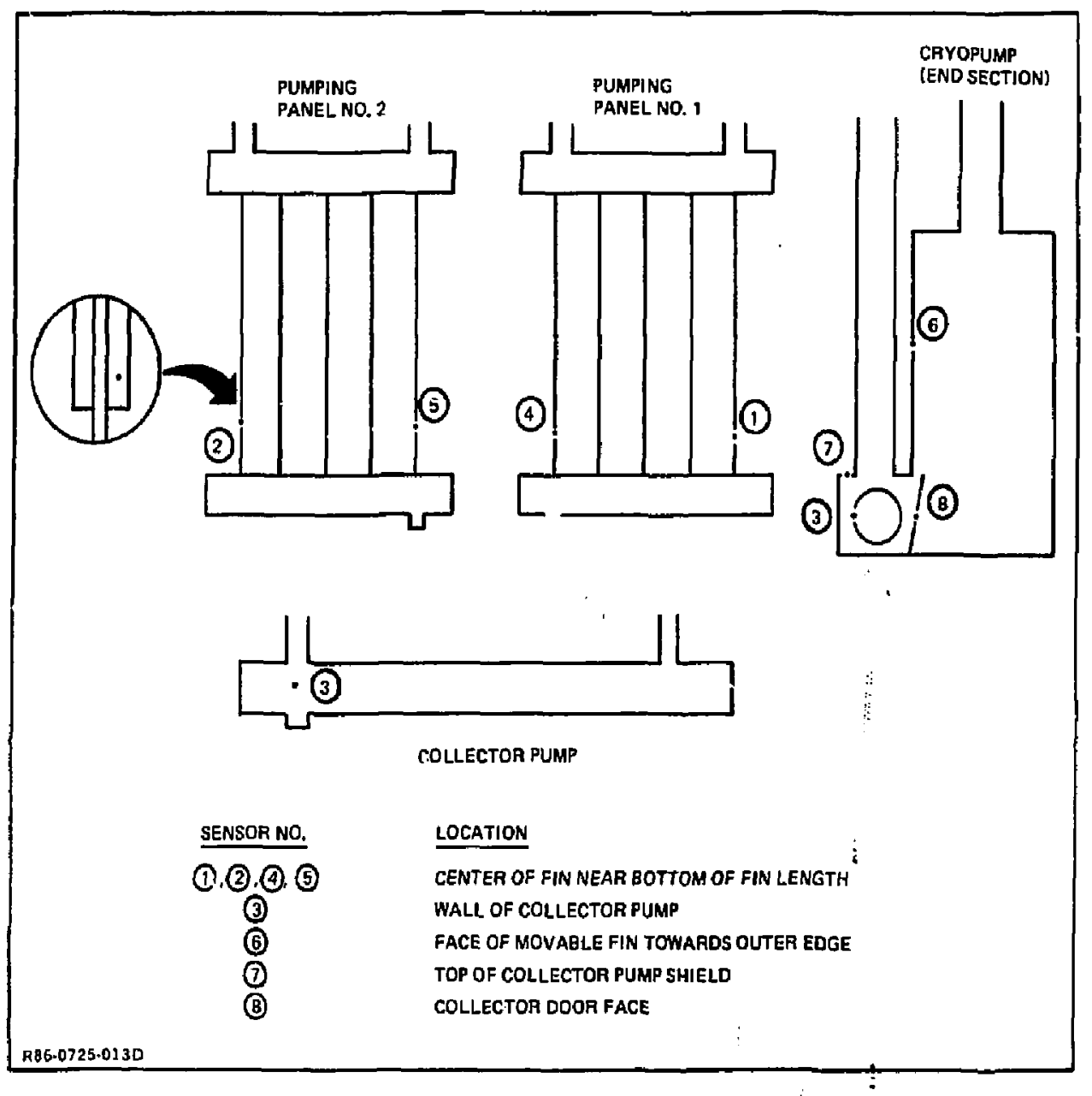

Fig. 13 Location of Tompernture Sonsors on Cryopump - Temperature stailus is resd at the control console. On an operational pump, the temperature reading could control the regeneration cycle time.

The instrumentation/control center is shown in Fig. 2. The control unit (center) includes monitors for temperature and level indicators; a system schematic showing position of automatic valves, doors, and louvers; a switch panel for manual operation of the pump, stop buttons, and auto/direct selector switch; ond the microprocessor controller with keyboard. This center is fully described in Pef. 4. Flow control and monitors, pressure monitors, and RGA readouts are installed in the left cabinet. 
Selection through the keyboard of antomatic mode of operation causes the cryopump to cycle continuously through a series of events as follows:

EVENT

PUMPING UNIT 1 PUMPING UNIT 2

1

Pumping

Regenernting

2

Pumping

Cooling Down

3

Regenernting

Pumping

4

Cooling Down

Pumping

A cycle is completed euch time Event 4 is completed. At the end of a predetermined number of cycles the controller pauses to allow manual regeneration of the collector pump. The doors between each pumping unit and the collector unit close for collector regeneration; however, the cryopump is configured to continue to pump the vacuum chamber. At completion of collector pump regeneration, the controller is keyed to proceed to Event 1 to resume automatic cycling. 


\section{6 - TEST PROCEDURE}

The test program consisted of the following procedures, which included preparing the pump for performance testing and establishing base conditions, verifying pump operation in manual mode, determining back-leakage, and performing pump operation and regeneration tests in automatic mode.

\subsection{PREPARATION FOR TEST}

The vacuun chamber was rough pumped by the external west pumping station, and then was pumped into the low $10^{-7}$ Torr range by the pumping station and by the CDC shields that were filled with liauid nitrogen. After the pumping station was valved off, chamber pressure increased, indicating a helium leak in a CDC panel. The leak was determined to be sufficiently low, and therefore did not affect tegi results (see Subsection 7.1); however, the pumping station was allowed to pump the chamber throughout the tests to offset the leak.

Before starting the CDC performance tests, the pressure rise rate $(\dot{\mathrm{P}})$ in the vacuum chamber was observed with a fixed nitrogen throughput $(Q)$ of $1.8 \times 10^{-3}$ Torr liter sec ${ }^{-1}$ with the pumping station valved off. Chamber volume (V) was determined from $V=\dot{Q} / \dot{P}$.

The three transfer lines were installed in the pump, and the dewars filled with liquid helium. When initial pressure and temperature equalization was reached, the temperature on a pumpirg unit helium dewar read unexpectedly high and liquid helium consumption was high. The problem was resolved by opening the pumping unit dump valves (Fig. 12) (see Subsection 7.1), and leaving them open for the conduct of the tests (electrical cables were disconnected). This procedure equalized the helium pressure between the fill and vent sides of the liquid helium-filled panels.

\subsection{DIRECT MODE TEST}

A series of runs was made with nominal deuterium throughputs to the vacuum chamber of 0.054 and 0.11 Torr liter $s^{-1}$, with control in the direct (manual mode). 
Each pumping unit was cycled through the events shown in Subsection 5.2 , thus verifying its proper operation.

\subsection{BACK LEAKAGE TEST}

- In order to estimate the back leakage from the pump interior to the vacuum chamber during regeneration, a run was made with a set of louvers closed and the corresponding pumping unit's dewar filled with liquid helium. The other pumping unit with louvers open was allowed to warm above the deuterium condensation temperature. In this configuration, deuterium pumping was effected through the closed louvers. Deuterium throughput was set at 0.03 Torr liter $s^{-1}$ for this leakage run.

\subsection{AUTOMATIC MODE TEGT}

The cryopump system was prepared for operation in the outomatic mode. The control program was loaded into the microprocessor controller (MPC) and the event times were programmed at eight minutes for Events 1 and 3 and 19 minutes for Events 2 and 4 . The pump dewars were refilled with liquic helium. Direct mode was selected and the cryopump valves and actuators were preset on the switch panel to the combination for Event 2 (Fig. 14). The dump valve electrical connections remained disconnected with the valves upen, so that the commands to these valves were overridden. The MPC was commandet through keyboard entry to "Start Sequence," and the pump was repetitively commanded through the events, starting with cooling of pumping panel 2 (Event 2). Constant deuterium throughputs ranged from 0.013 Torr liter $\mathrm{s}^{-1}$ to 13.6 Torr liter $\mathrm{s}^{-1}$. The collector pump was regenerated periodically.

Chamber prєssure, temperature, and deuterium flow rate were recorded at appropriate intervals during each test. A strip chart recorded chamber pressure during regeneration of the pumping units and the collector pump. 


\begin{tabular}{|c|c|c|c|c|c|c|c|}
\hline \multirow{2}{*}{ VALVEJACTUATOR } & \multirow[t]{2}{*}{ MOMENCLATUAE } & \multicolumn{6}{|c|}{ EVENT } \\
\hline & & 1 & 2 & 3 & 4 & 5 & 6 \\
\hline $\begin{array}{l}\text { PURGE } 1 \\
\text { VENT 1 } \\
\text { FILL COLLECIOR } \\
\text { FILL } 1 \\
\text { DUMP } 1 \\
\text { DUMP } 2 \\
\text { FILL } 2 \\
\text { PURGE } 2 \\
\text { VENT } 2 \\
\text { LOUVEA } 2 \\
\text { COLLECTOA DOOR } 1 \\
\text { COLLECTOR DONR } 2\end{array}$ & $\begin{array}{l}P 1 \\
V 1 \\
F C \\
F 1 \\
D 1 \\
D 2 \\
F 2 \\
P 2 \\
V 2 \\
\text { L2 } \\
\text { CD1 } \\
C D 2\end{array}$ & $\begin{array}{l}\text { c } \\
0 \\
0 \\
0 \\
c \\
0 \\
C \\
0 \\
c \\
c \\
c \\
0\end{array}$ & $\begin{array}{l}\text { c } \\
\text { o } \\
\text { o } \\
\text { o } \\
\text { c } \\
\text { c } \\
\text { o } \\
\text { c } \\
0 \\
\text { c } \\
\text { C } \\
\text { c }\end{array}$ & $\begin{array}{l}0 \\
c \\
0 \\
c \\
0 \\
c \\
0 \\
c \\
0 \\
0 \\
0 \\
c\end{array}$ & $\begin{array}{l}\text { c } \\
0 \\
0 \\
0 \\
c \\
c \\
0 \\
c \\
0 \\
0 \\
c \\
c\end{array}$ & $\begin{array}{l}c \\
0 \\
c \\
o \\
c \\
c \\
0 \\
c \\
0 \\
c \\
c \\
c\end{array}$ & $\begin{array}{l}\text { C } \\
0 \\
0 \\
0 \\
\text { c } \\
\text { C } \\
\text { o } \\
\text { C } \\
\text { o } \\
\text { c } \\
\text { C } \\
\text { C }\end{array}$ \\
\hline \multicolumn{8}{|c|}{$\begin{array}{l}\text { NOTES: } \\
\text { LOUVERS } 1 \text { AND } 2 \text { ARE CONNECTED SO THAT ONE IS OPEN WHILE THE } \\
\text { OTHEA IS CLOSED } \\
\text { O= OPEN } C=\text { CLOSED } \\
\text { REG-0725-014D } \\
\text { RES-0716-0326 }\end{array}$} \\
\hline
\end{tabular}

Fig. 14 Default Valva/Actuatur Positions - Positions are preprogrammed and controlled by automatic sequencer. Collector pump is regenerated mantally during events 5 and 6. 


\section{7 - TEST RESULTS}

The characteristics of the continuous duty cryopump system were determined by operating and observing the system in the modes described in Section 6.

\subsection{PRETEST CONDITIONING}

Pump temperatures were monitored throughout the series and are shown in Fig. 15. Temperature distribution of the liquid nitrogen-cooled shield was influenced little, whether the dewars were helium-filled or not, or whether the pumping units were regenerating, cooling down, or pumping. The monitored temperature ranged from 85-88 deg $K$ at the outer edge of the fin, 85-90 deg $K$ on the collector cover, and 90-93 deg $K$ on the collector door compared to predicted values of 92,117 , and $94 \mathrm{deg} \mathrm{K}$, respectively.

\begin{tabular}{|c|c|c|c|c|c|c|c|c|c|}
\hline $\begin{array}{l}\text { TEST CONDITION } \\
\text { [CHRONOLOGICAL OVER } \\
\text { 2.OAY TEST PERIOD] }\end{array}$ & $\begin{array}{c}\text { D2 } \\
\text { FLOW } \\
\text { TORR.L/S }\end{array}$ & $\begin{array}{c}\text { TEM } \\
1\end{array}$ & $\begin{array}{l}\text { RAT } \\
2 \\
\text { TEW }\end{array}$ & $\begin{array}{l}\text { IE SEI } \\
3 \\
\text { RATI }\end{array}$ & $\begin{array}{c}\text { OR LO } \\
4 \\
\text { IE (K) }\end{array}$ & & 6 & 7 & 8 \\
\hline 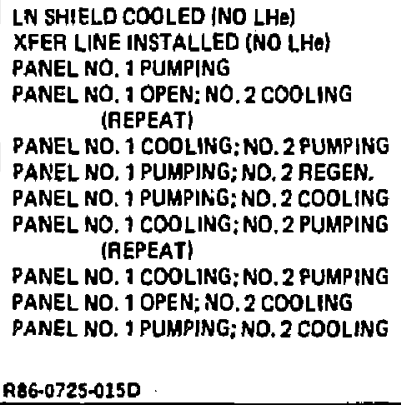 & $\begin{array}{c}- \\
- \\
0.06 \\
0 \\
0 \\
0.11 \\
0.11 \\
0.11 \\
0.11 \\
0.11 \\
0.69 \\
0 \\
13.6\end{array}$ & $\begin{array}{l}150 \\
155 \\
5.3 \\
5.4 \\
5.3 \\
\vdots \\
\vdots \\
5.1 \\
5.1 \\
5.4 \\
5.5 \\
- \text { NO }\end{array}$ & $\begin{array}{c}137 \\
142 \\
5.1 \\
5.1 \\
5.1 \\
\vdots \\
\vdots \\
5.3 \\
5.3 \\
5.1 \\
5.2\end{array}$ & $\begin{array}{l}158 \\
161 \\
5.6 \\
6.1 \\
58 \\
\vdots \\
\vdots \\
5.7 \\
5.7 \\
5.8 \\
5.9\end{array}$ & $\begin{array}{c}143 \\
147 \\
5.3 \\
5.3 \\
5.3 \\
4.8 \\
\vdots \\
. \\
4.7 \\
4.8 \\
4.7 \\
5.3 \\
5.5\end{array}$ & $\begin{array}{c}131 \\
135 \\
4.5 \\
4.6 \\
4.5 \\
22.6 \mathrm{MAX} \\
4.6 \\
5.2 \\
5.2 \\
4.6 \\
4.6\end{array}$ & $\begin{array}{c}86 \\
86 \\
86 \\
86 \\
88 \\
\vdots \\
\vdots \\
86 \\
86 \\
85 \\
86\end{array}$ & $\begin{array}{c}90 \\
90 \\
86 \\
88 \\
87 \\
\vdots \\
\vdots \\
85 \\
85 \\
85 \\
85\end{array}$ & $\begin{array}{c}91 \\
92 \\
9 \\
93 \\
91 \\
\vdots \\
\vdots \\
90 \\
90 \\
90 \\
92\end{array}$ \\
\hline
\end{tabular}

Fig. 15 Survey of Cryopump Temperatures - Pumping panel is fully regenerated before its temperature rises to $22,6 K$.

After fllling the pumping unit dewars with helium, an elevated dewar temperature reading and an unexpectedly high helium consumption indicated the presence of a thermal short and/or presence of vapor in the dewar. Investigation showed that by opening the pumping unit dump valve, the problem was corrected. Evidently the 
closed column below the valve allowed warmer gas to be forced down into the dewar. The dump and vent valves serve similar functins, in that they allow helium to leave the dewar. The design purpose of the vent valve is to vent helium normally boiled off during pumping, and the dump valve is to dump helium purged out by ambient gas for regeneration. In the test setup, the vent and dump lines joined at a manifold upstream of the valves to a common return to the refrigerator; no attempt was made to segregate the cryogenic helium returned at different energy levels, whereas one would do this in an operational installation. Therefore the dump valves were allowed to remain open throughout the tests to resolve the problem.

Base pressure $P_{0}$ was $1.3 \times 10^{-7}$ Torr prior to filling the panels with liquid helium, with liquid nitrogen in the cryopump and with the west station pumping the chamber. This anexpectedly high pressure indicated a leak, which was subsequently traced to one of the cryopump's pumping panels. The leak rate was cletermined as follows: the west station's pumping speed $\left(S_{w}\right)$ was determined from $S_{w}=N_{1} / P_{1}$ by inflowing a fixed tluroughput of nitrogen $N_{1}\left(3.55 \times 10^{-3}\right.$ Torr. liter. $\left.s^{-1}\right)$, and measuring the pressure $P_{1}\left(2.0 \times 10^{-5}\right.$ Torr $)$. $S_{w}$ was 177 liter $s^{-1}$. Leak flow $\left(Q_{L}\right)$ calculated from $Q_{L}=P_{0} S_{W}$ was $2.3 \times 10^{-5}$ Torr-liter $s^{-1}$. This small leak was determined to be in the LHe pumping panel, therefore, the west station's turbomolecular pump was used to pump the helium.

The vacuum chamber volume (V) was estimated using the pressure rise method with the pumping station valved off. With only the helium leals flow into the chamber volume, the rise rate was $5.9 \times 10^{-9} \operatorname{Torr}^{-1}$, and was $4.8 \times 10^{-7}$ Torr. $\mathrm{s}^{-1}$ while $1.78 \times 10^{-3}$ Torr liter $s^{-1}$ nitrogen was inputted. Fvaluating volume from flow rate ratioed to pressure rise rate gave a chamber volume of 3,800 liters $\pm 2 \%$.

\subsection{PUMP PERFORMANCE}

Deuterium pumping speed was determined from throughput and vacuum chamber pressure for test runs made in the automatic and manual mode. Speed was referenced to pressure gages placed at the chamber wall in line with the pump entrance (east gage), and in the vicinity of the deuterium gas supply (west gage). The results, presented in Fig. 16, show that the pump yerformance referenced to the pump entrance exceeds the design speed of 8 liter $\mathrm{sec}^{-1} \mathrm{~cm}^{-2}$ deuterium $\mathrm{gt}^{t} 10^{-5}$ Torr ( 0.124 Torr liter $\sec ^{-1}$ per fief. 4; pump entrance area $\left.=1,584 \mathrm{~cm}^{2}\right)$. The 


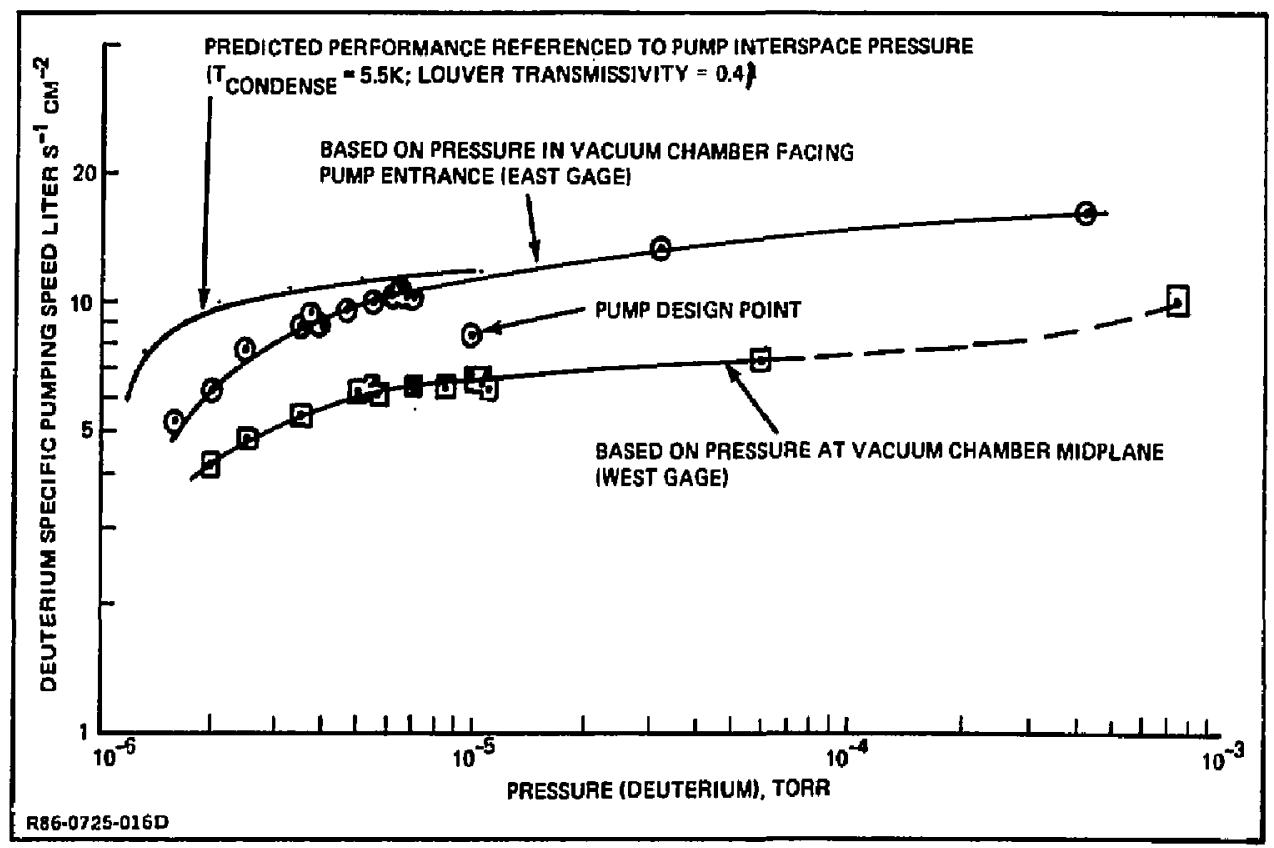

Fig. 16 Dwuterium Pumping Parformance of the Continuous Duty Cryopump - Speed is constant at a given rondition and fixed flow rate. Design point referenced to pump inlet is besed on Vecherron design.

correlation for cryocondensing pump speed developed in Ref. 6 was used and included in the figure for reference to show performance trends based on a deuterium condensation temperature of $5.5 \mathrm{deg} \mathrm{K}$ and louver transmissivity of 0.4 .

The capability of the pump was tested over a wide range of deuteriun throughputs. At low flow rates and corresponding low pressures, performance diminished indicating that the pump interspace pressure was approaching the deuterium vapor pressure at the pumping panel's temperature. At high yacuum chamber pressure the increased performance is indicative of onset of transition flow (transition from molecular flow to viscous flow). No indication of thermal runaway wes observed for the run at pressures approaching $10^{-3}$ Torr.

The vacuum chamber time constant referenced to the pump entrance speed at $10^{-5}$ Torr is $0.2 \mathrm{sec}$. 


\subsection{BACK LEARAGE DURING REGENERATION}

Deuterium pumping speed was determined for the pump with its louver closed as a means of estimating back leakage from the pump cavity to the vacuum chamber during regeneration. With one pumping unit cooled to liquid helium temperature and its louver in the closed position, a constant flow of 0.03 Torr liter sec $^{-1}$ deuterium was introduced to the vacuum chamber. Chamber pressure in the vicinity of the inflow ( $P_{\text {west }}$ in Fig. 10) held at $3.5 \times 10^{-5}$ Torr, indicating a deuterium pumping speed through the closed louvers of 855 liter/sec. This speed is $7.5 \%$ of the pump speed with the louvers open.

Chamber pressure measured (at the west station) during regeneration of a pumping panel unit or of the oollector pump is an indication of the effect of back leakage. The pressure histories shown in Fig. 17 to 21 result from regeneration of a pumping panel unit following a period of pumping by that panel. Figure 22 shows the pressure during collector pump regeneration, following a series of cycles.

A typical programmed cycle followed the sequence of events and times stated in Subsection 5.3. The panel pumped for $27 \mathrm{~min}$, regenerated for $8 \mathrm{~min}$, cooled down for $19 \mathrm{~min}$ and resumed pumping for $27 \mathrm{~min}$. Actual cooldown was significantly less then the programmed $19 \mathrm{~min}$; helium fill was shut off automatically by the level controller when the pumping unit dewar indicated full. During the regeneration event, ambient helium, introduced automatically through the purge valve, displaced the liquid helium. The appropriate purge flow was determined (by trial) by varying the ambient helium legenerator pressure. The flow rate was not measured, however, the required purge flow was minimal. Note that the act of closing the dump valves was sufficient to push out the helium (Subsection 7.1).

The regeneration pressure profiles shown in Fig. 17 and 18 follow 27 min of deuterium pumping by panel 1 and 2 , respectively, at 0.12 Torr liter $\mathrm{s}^{-1}$. The corresponding temperature profile for panel 1 regeneration is shown in Fig. 23 indicating that liquid helium is purged from the dewar of the pumping unit at approximately $4.8 \mathrm{~min}$ after start of purge. The principal pressure disturbance in the vacuum chamber, which occurs after this time, peaked at $1.3-1.5 \times 10^{-4} \operatorname{Torr}\left(\mathrm{N}_{2}\right.$ equivalent) or 3.3 to $3.8 \times 10^{-4}$ Torr (deuterium). These high values are expected with the prototype pump configuration that was tested. Lower pressure disturbances are projected for operational installations (see Subsection 8.3). 


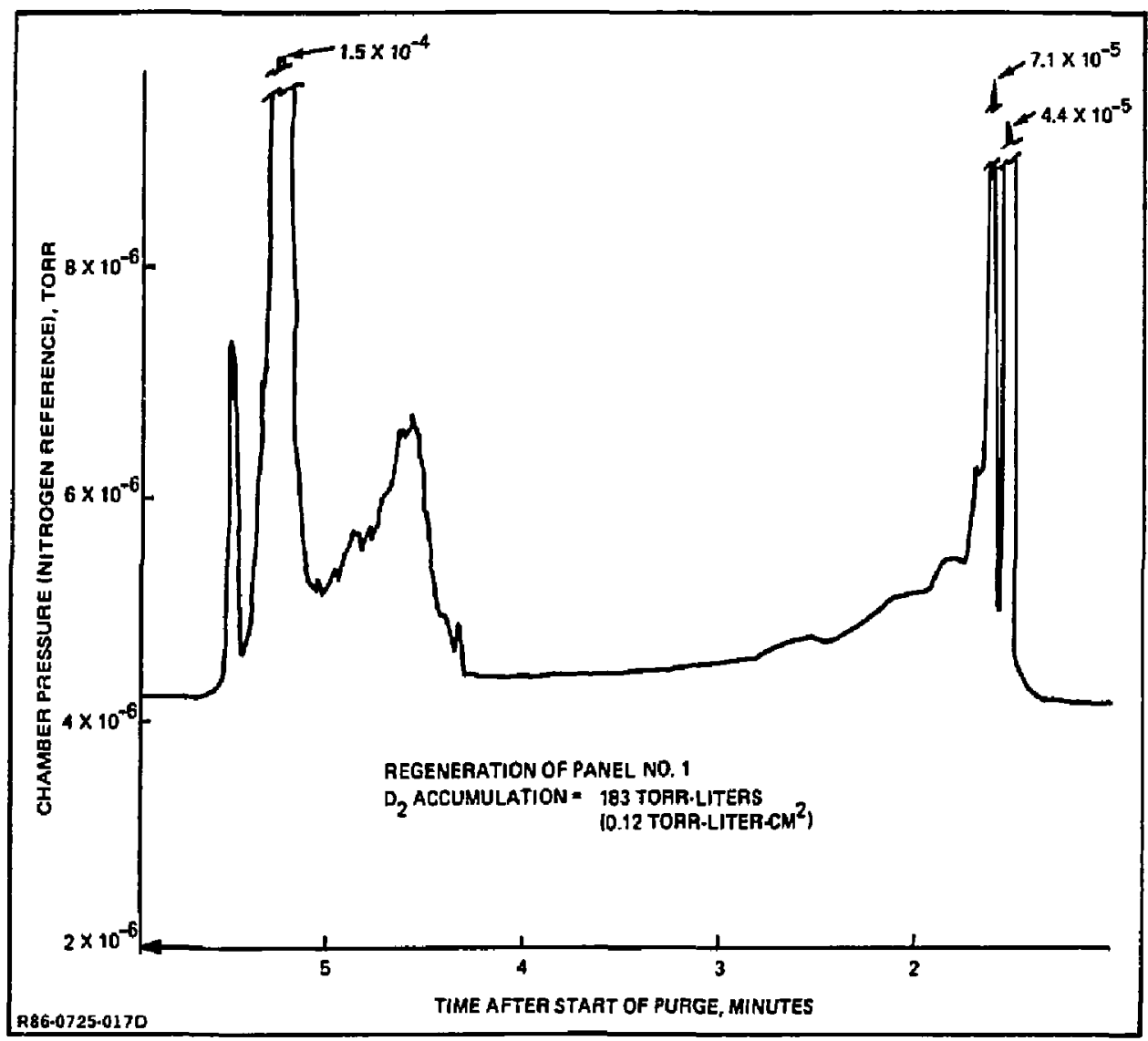

Fig. 17A Vacuum Chember Presure History During Repaneration - Pand 1 is regenefated after 183 Torr liters accumulation. Figure reprootuces actual dato trace.

The vacuum chamber pressure peak (Fig. 19) at regeneration following 27 min

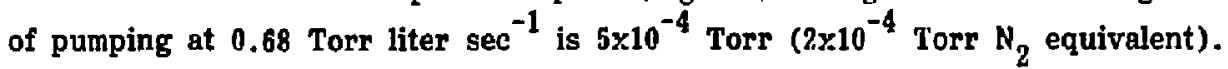
The corresponding pressure profiles at regeneration following pumping of a constent 13.65 Torr liter $\mathrm{s}^{-1}$ throughput rate (for $19 \mathrm{~min}$ for panel 1 and 27 min for panel 2) are shown in Fig. 20 and 21. Pressure peaks to $2.5 \times 10^{-3}$ Torr $\left(10^{-3} \operatorname{Torr} \mathrm{N}_{2}\right.$ equivalent) were observed.

The collector pump was regenerated after a total cryopump continuous run time of 141 min of deuterium pumping at 0.11 Torr liter $\sec ^{-1}$. Before regeneration, the two pump collector doors were closed, deuterium throughput was stopped, and the roughing valve to the east pumping section was opened. Vacuum chamber pressure 


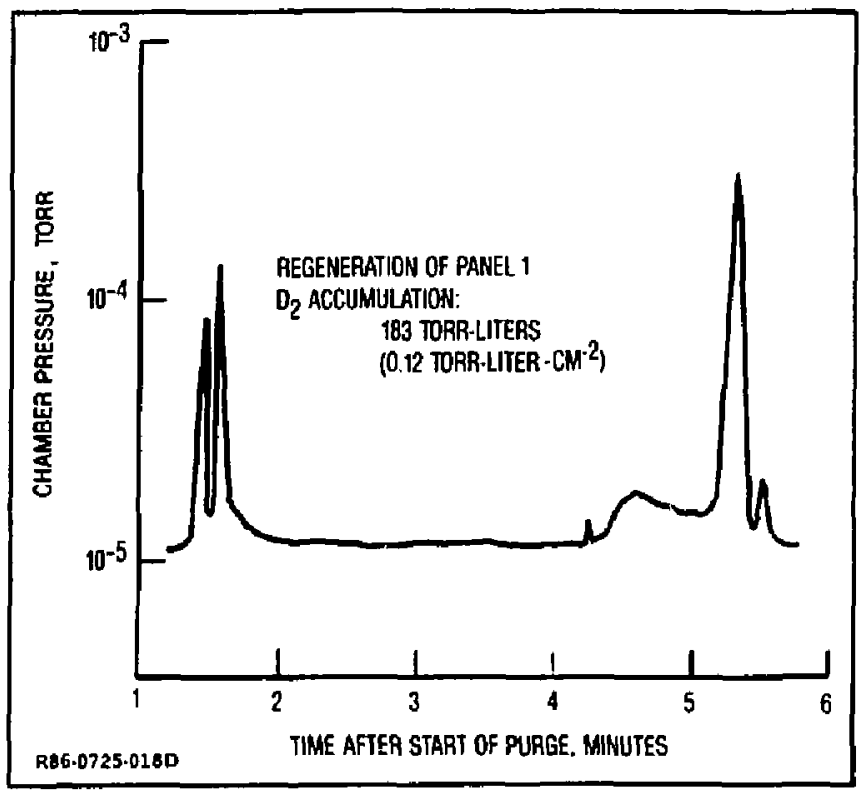

Fig. 178 Vecuum Chamber Prosure History During Regameration - Dats of Fig. 17A is redrawn with pressure corrocted for deuterium. Maximum pressure will not exceed the mid $-10-5$ Torr range in operational installation.

rose to $10^{-4}$ Torr $\left(4 \times 10^{-5}\right.$ Torr $\mathrm{N}_{2}$ equivalent) after 10-11 nin of ambient helium purge.

\subsection{CRYOPUMP SYSTEM CONTINUOUS OPERATICN}

The cryopump operated continuously without operator intervention, from the command at the keyboard for start of automatic sequence operation until the test was ended by switching to direct (manual) operation using the auto/direct switch on the control panel. Changes in deuterium throughput rate were made without interrupting the pump operation. Panel lights indicuted changes in valve and actuator status as the test progressed through the preprogrammed events and cycles. The valve operations, which were commanded automatically for regeneration of the pumping units, were performed by hand for the collector pump regeneration, with the exception of the automatic fill valve.

Deuterium pumping speed at a given throughput remained constant as deuterium accumulated in the pumping units for the duration of each test. Pumping performance of panel 1 was in agreement with that of panel 2 . 


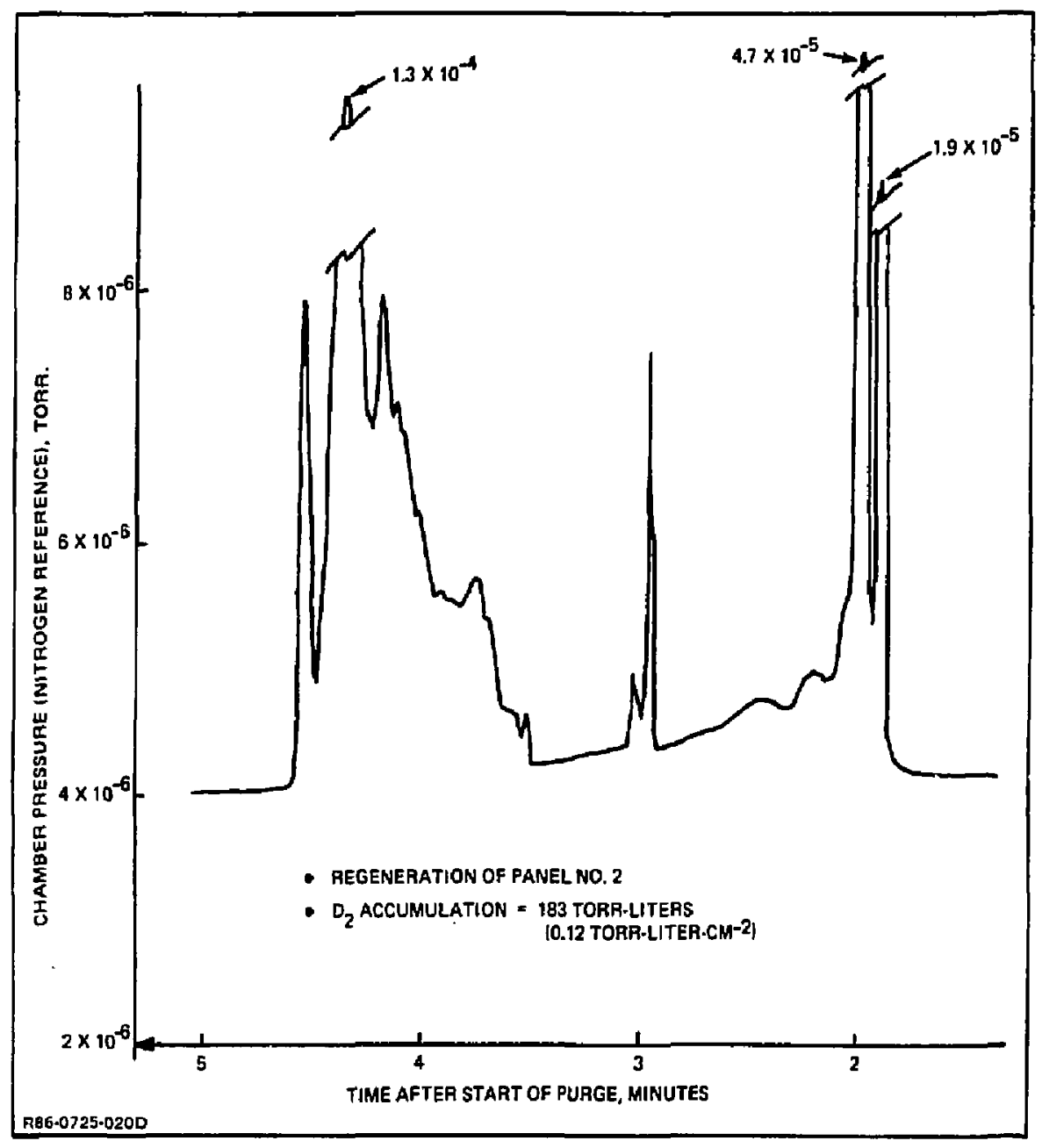

Fig. 18 Vacuum Chamber History During Aegeneration - Panel 2 is regenerated after 183 Torr-liters sccumulation. 


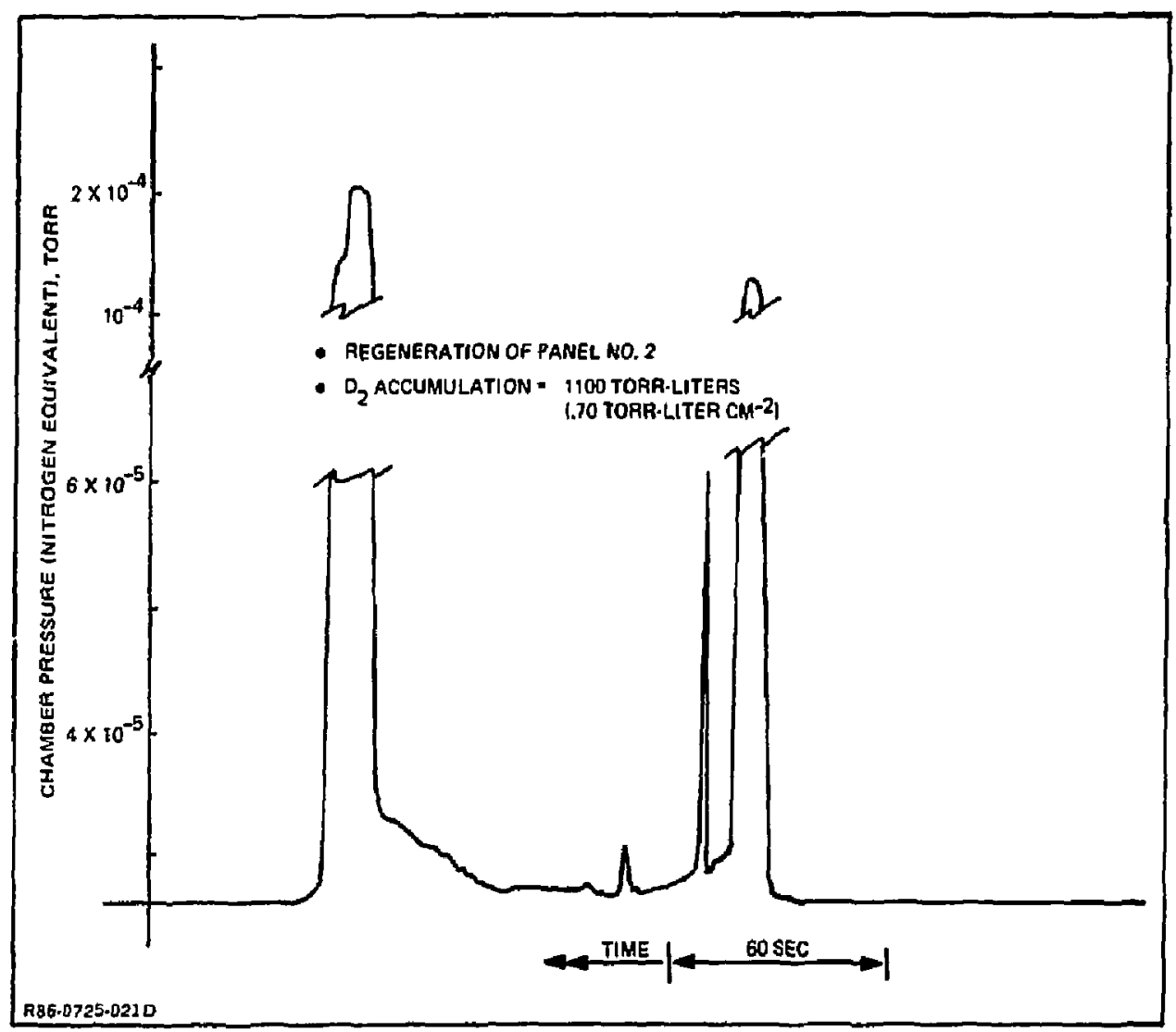

Fig. 19 Vacuum Chamber Pressure History During Rapamaration - Panel 2 is regenerated after 1100 Torr.liters accumulation. 


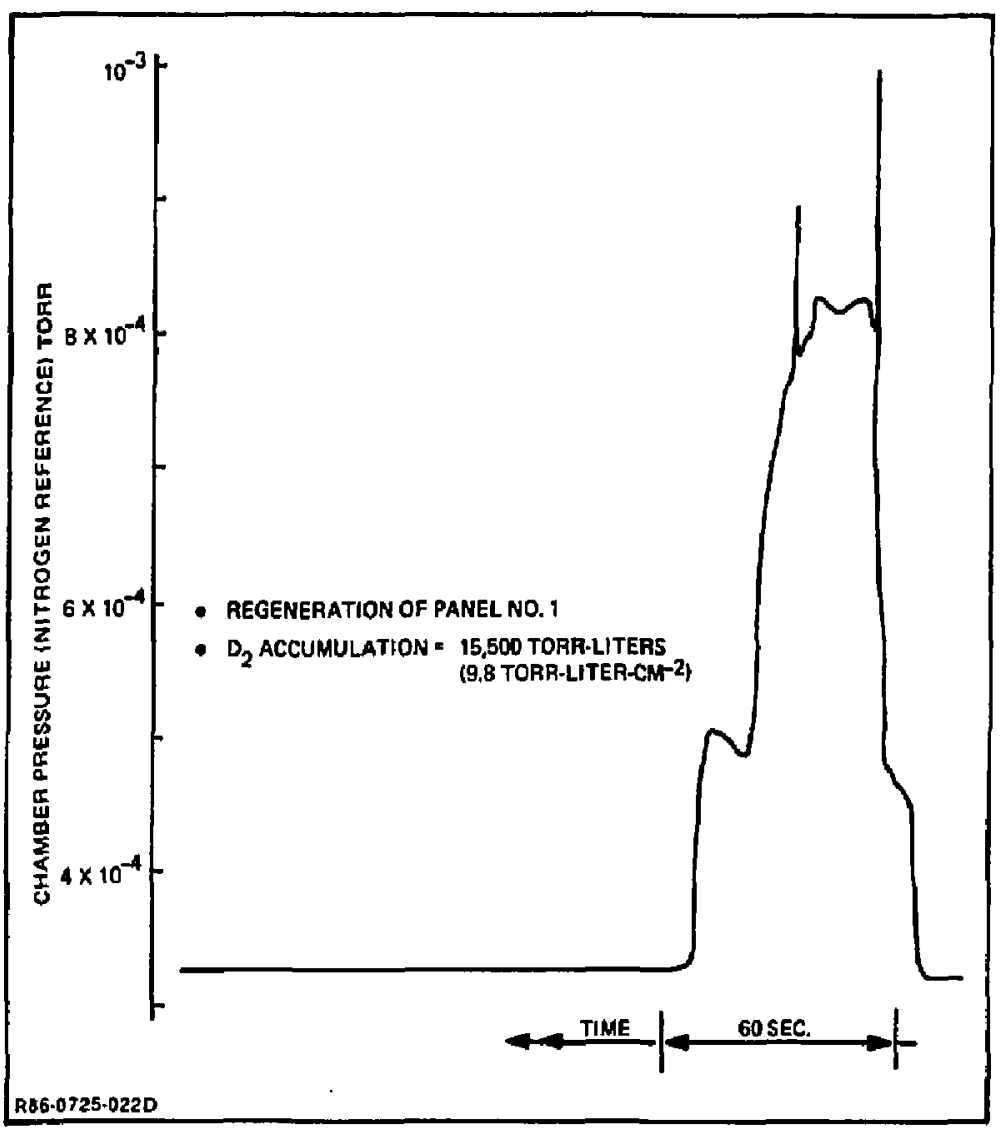

Fig. 20 Vacuum Chamber Presure Hintory During Reponoration - Panel 7 is regenerated after 15,500 Torr-liters accumulation. 


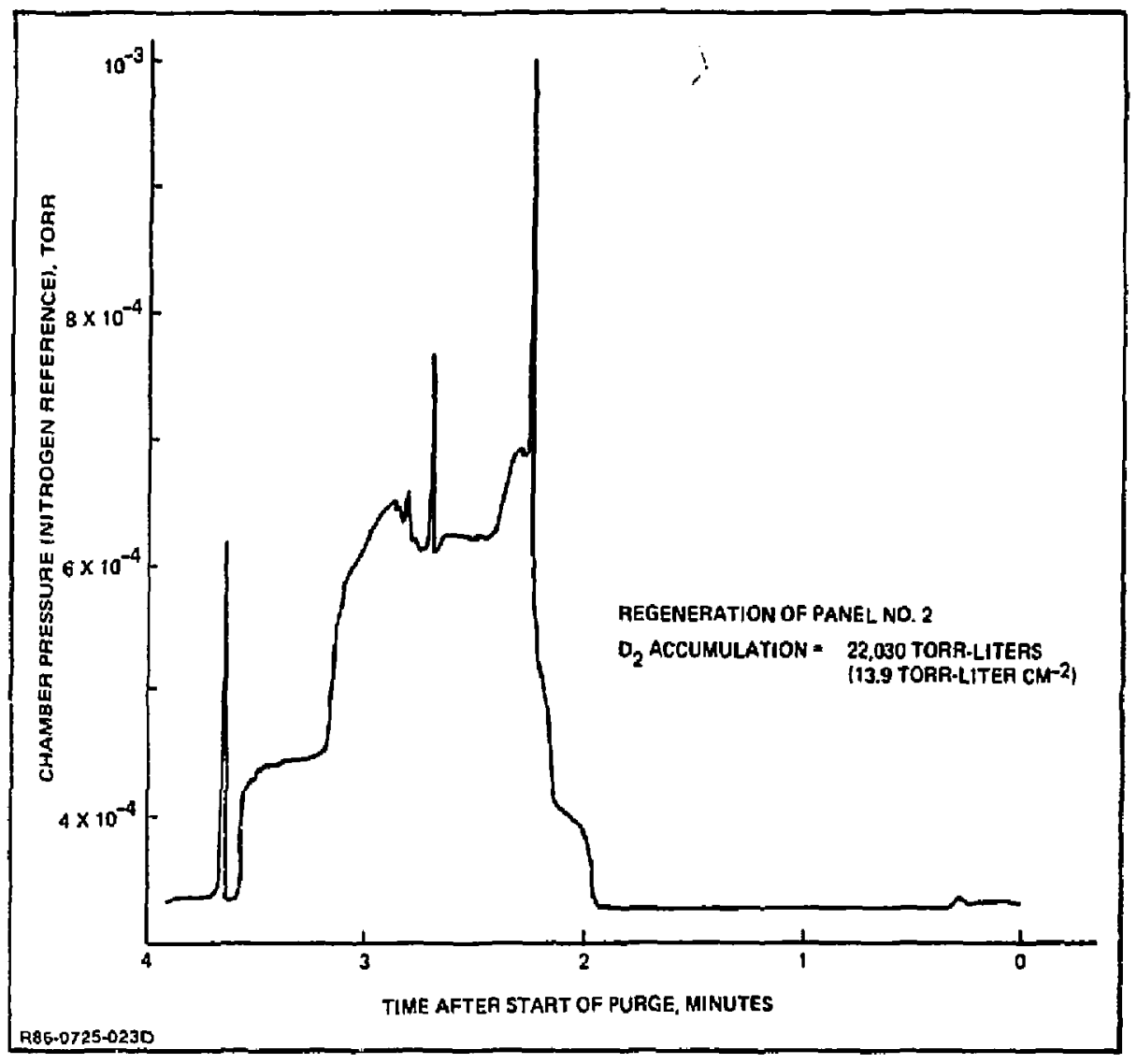

Fig. 21 Vacuum Chamber Presura History During Pand Reganoration - Panel 7 is regenerated after 22,030 Torr-/iters accumulation. 


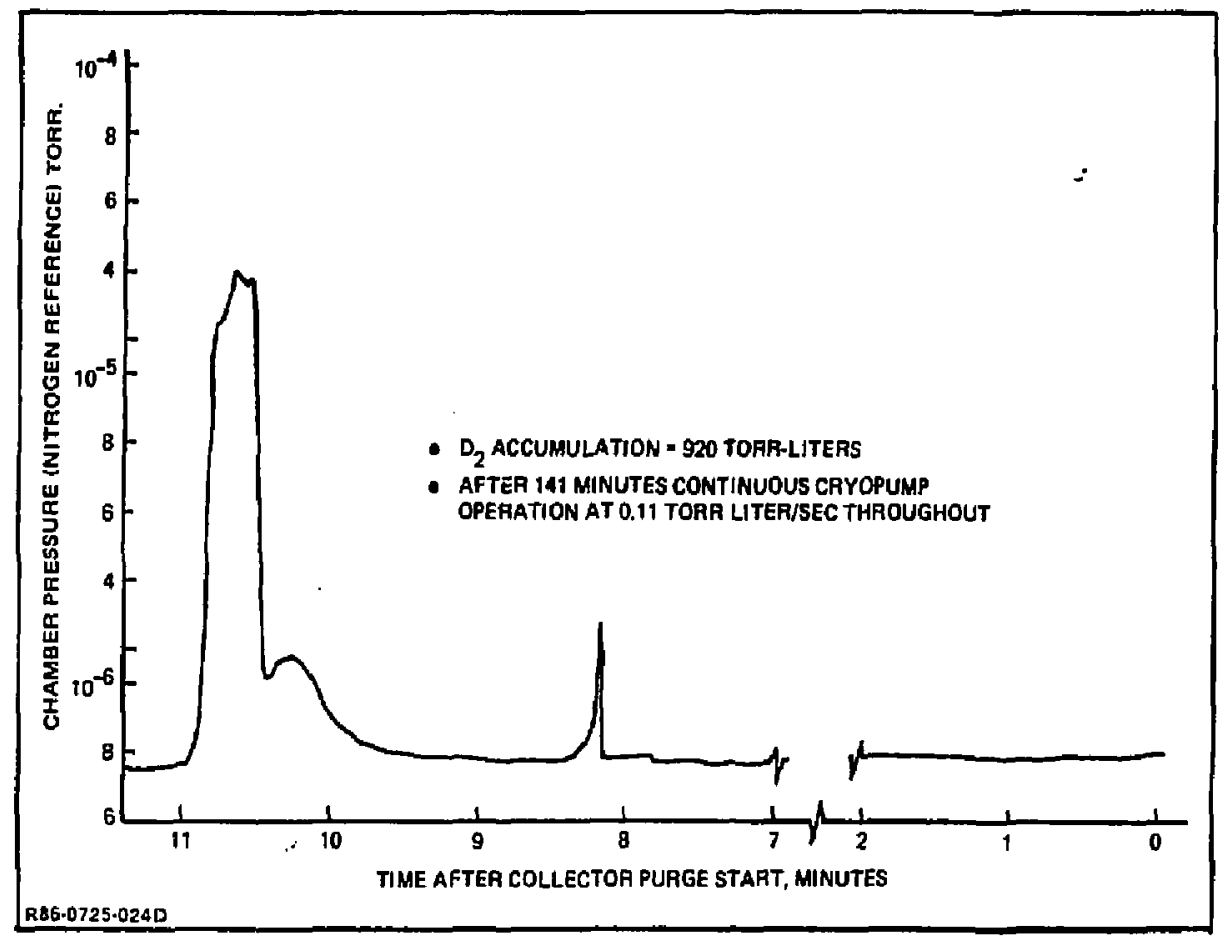

Fig. 22 Vacuum Chamber Proweurs History During Collector Pump Regeneration - Pump is regenerated after 920 Torr-liters accumulation. 


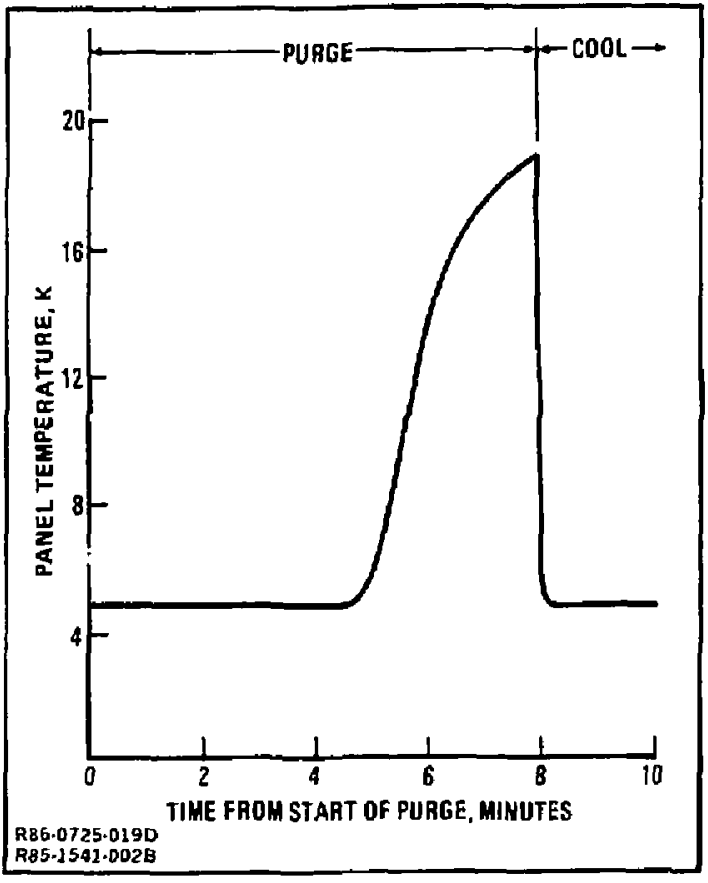

Fig. 23 Typieal Regenaration Temperature Profile (Punal 1). Regenerated gas is relested in less then six minutes. Corresponding chamber history is shawn in Fig. 17A. 


\section{8 - DISCUSSION}

\subsection{PRETEST EVALUATION}

The liquid nitrogen shield provided efficient thermal protection for the liquid helium-ccoled pumping units and the collector pump. The shield, which was conductance cooled by integral nitrogen dewars, reached a maximum temperature of $93 \mathrm{deg} \mathrm{K}$. Temperatures at the tip of the movable louver were 85-88 deg K, a condition that veriffed the efficient thermal conductance of the aluminum foil bridge used to by-pass the louver hinge (Ref. 2 and 4).

The cryopump was designed with separate holium return lines, so that vapor vented during pumping and colder helium dumped during regeneration could be sent, in an operational installation, to different stages of a refrigerator/liquefier. The vent and dump valves would not be open or closed at the same time. It was observed in test preparation that closing the dump valve (while the vent was open) caused a high helium consumption rate and that opening the dump valve corrected this condition. Figure 12 shows that any gas formed under the closed dump valve would be driven down into the pumping unit's upper dewar, causing liquid helium to flash and be driven out the vent. A recommended design modification is to provide a jumper line upstream of the valves between the vent and dump lines to allow venting from the closed dump line without inadvertently purging the dewar.

\subsection{PUMP PERFORMANCE}

The pumping speed (Fig. 16) for deuterium measured at the pump entrance is 17,40n liter $\mathrm{sec}^{-1}$ (11 liter $\mathrm{sec}^{-1} \mathrm{~cm}^{-2}$ ) at chamber pressure equal to $10^{-5}$ Torr, indicating transmissivity for the louver of 0.35 . This value is in general agreement with Ref. 6, which projects a $30 \%$ conductance improvement compared to a conventional chevron shield. The comparable speed in the chamber at the location of the deuterium in-flow (Fig. 10) is 10,300 liter $\mathrm{sec}^{-1}\left(6.5\right.$ liter $\mathrm{sec}^{-1} \mathrm{~cm}^{-2}$ referenced to the pump's projected inlet area), which indicates a total conductance fraction from this location to the pumping panel surface of 0.20 . The effect of panel placement in a vacuum chamber was analyzed extensively in Ref. 7. Although optimized pump placement was not an objective of this test program, the importence of placement has 
been illustrated.

\subsection{BACK LEAKAGE DURING REGENERATION}

The regenerable pump built by Batzer and Call (Ref. 2) was the prototype for the pump tested here. The referenced pump's back leakage was estimated to be as high as 30\%. Although optimizing the design to minimize back leakage was not an objective of that program, the effost showed the features that would allow attainment of an estimated 5-108 leakage rate, which would be acceptable. These featurcs, 1.e., close fitting louvers, optimized conductance between the pump unit and the collector pump, and increased collector pump speed werc implemented (Ref. 4). The projected leakage during regeneration, besed on a calculated pumping speed with the louvers closed, is 7.58. Although this value could be reduced further by improved fit, for example between the top or bottom of the movable louvers and the pump housing, the concern during regeneration is the effect of any back leakage on chamber pressure.

The fraction of pumped gas leaking back to the racuum chanber during regeneration causes a pressure rise. The peaks are shown for the cryopump in Fig. 17 to 21 and the equivalent peak pressures (deuterium) ara shown in Fig. 24 .

\begin{tabular}{|c|c|c|}
\hline $\begin{array}{c}\text { PUMP BEING } \\
\text { REGENERATEO }\end{array}$ & $\begin{array}{c}\text { DEUTERIUM } \\
\text { ACCUMULATION } \\
\text { TORR-LITERS/TORR-LITERS CM }\end{array}$ & $\begin{array}{c}\text { DEUTERIUM PEAK } \\
\text { PRESSURE IN CHAMBER } \\
\text { TORR }\end{array}$ \\
\hline PANEL 1 & $183 / 0.12$ & $3.8 \times 10^{-4}$ \\
PANEL 2 & $183 / 0.12$ & $3.3 \times 10^{-4}$ \\
PANEL 2 & $1100 / 0.7$ & $5 \times 10^{-4}$ \\
PANEL 1 & $15.500 / 9.8$ & $2.5 \times 10^{-3}$ \\
PANEL 2 & $22.030 / 13.9$ & $2.5 \times 10^{-3}$ \\
COLLECTOA & $920 /-$ & $10^{-4}$ \\
& & \\
\hline
\end{tabular}

Fig. 24 Peak Chanber Pressure From Backleakage During Regeneratiorı of Test Cryo. pump - Peak presures are higher than are expected with operaitonal fusion cryopump. Pumping time will be limited by $T_{2}$ inventory.

Lower values are expected for an operational installation. The test cryopump has 1008 excess capacity, i.e., one unit is offline for regenexstion while one unit is pumping. A more reasonable chnice for an operational pump systen is one witt an excess capacity of lip to $20 \%$, i.e., five units pumping to one unit regenerating (Ref 2). With such an arrangement, one yould expect the peak pressures in on opera- 
tional installation to be one-fifth the observed values. Tritium accumulation on a cryopump for a fusion device is the factor that limits the time between regenerations. Although a standard for allowable tritium accumulation has not been established, a maximum allowable amount of less that 0.06 Torr - liter for each square centimeter of pump inlet area is predicted. This amount corresponds to under $30 \mathrm{~g}$ tritium held up in the cryopumps of a $1500 \mathrm{MW}$ fusion device. With these qualifications, the niaximum peak pressure sensed in the vacuum chamber during regeneration of a pumping unit (in a six-unit installation) is predicted to be limited to a maximum of about $3 \times 10^{-5}$ Torr. Further care in design could probably lower this value by a factor of 2 to 4 .

\subsection{CRYOPUMP SYSTEM CONTINUOUS OPERATION}

The cryopump system was operated continuously in both the direct mode, for which the operator commanded remote valves and actuators by resetting switches on the control panel, and the automatic mode, for which these same commands were issued by the controller program. In each case, the cryopump provided continuous deuterium pumping while the pump was periodically regenerated. Control of the cyclical events in automatic mode was open loop; the timing of each event was readily reprogrammed based on prior observations of pressures and temperatures in the chamber and the pump. A closed control system can be adepted readily to an operational cryopump system. 


\section{9 - CONCLUSIONS}

This program successfully demonstrated the capability to pump deuterium continuously using a cryopump system that can be regenerated periodically to minimize pumped gas inventory. Based on the results of these tests, one can design with confidence large scale, continuous cryopump systems with reliable performance for fusion reactor application, and that keep tritium inventory well under $100 \mathrm{~g}$. The test pump will be retrofltted with cryosorption surfaces to determine the characteristics of pumping and regenerating both helium and deuterium. 


\section{0 - REFERENCES}

1. Coffin, D.O. and Walthers, C.R., "Vacuum Pumping of Tritium in Fusion Power Reactors," Proceedings of the 8th Symposium on Engineering Problems of Fusion Research," IEEE Pub. No. 79 CH 1441-S NPS, (1979).

2. Batzer, T.K. and Call, W.R., "A Continuous Duty Cryopump for Steady-State Fusion Reactors," J Vac Sei Technol (2) 1315 (1983).

3. Mirror Advanced Reactor Study Interim Report, Lawrence Livermore National Laboratory, UCRL - \$3333 Pg 3-132, (1983).

4. Sedgley, D.W., "Design of a Continuous Duty Cryopump," Grumman Aerospace Corporation, ES-85-70, (1985).

5. Sedgley, D.W., Dietz, L.P., Szuchy, N.C., Batzer, T.H., and Call, W.R., "Development of a Continuous Duty Cryopump," Fusion Technology, Vol 8, (1985).

6. Pittenger, L.C., "Vacuum Engineering for Fusion Research and Fusion Reactors, $"$ 22nd Symposium American Vacuum Society, 1976.

7. Hood, C.B. and Bonn, J.W., CVI Corporation, "Large Scale Cryopumps for Fusion Power Systems," ASME Century 2 Publications, Aug 1980. 